Illinois State University

ISU ReD: Research and eData

Theses and Dissertations

3-27-2017

\title{
"I Didn't Even Think Of This": Examining The Influence Of Student Disability Accommodation Training On Basic Course Instructor Attitudes And Self-Efficacy
}

Jillian A. Joyce

Illinois State University, jajoyc1@ilstu.edu

Follow this and additional works at: https://ir.library.illinoisstate.edu/etd

Part of the Communication Commons

\section{Recommended Citation}

Joyce, Jillian A., "'I Didn't Even Think Of This": Examining The Influence Of Student Disability Accommodation Training On Basic Course Instructor Attitudes And Self-Efficacy" (2017). Theses and Dissertations. 725.

https://ir.library.illinoisstate.edu/etd/725

This Thesis is brought to you for free and open access by ISU ReD: Research and eData. It has been accepted for inclusion in Theses and Dissertations by an authorized administrator of ISU ReD: Research and eData. For more information, please contact ISUReD@ilstu.edu. 
“I DIDN'T EVEN THINK OF THIS”: EXAMINING THE INFLUENCE OF STUDENT

DISABILITY ACCOMMODATION TRAINING ON BASIC COURSE

INSTRUCTOR ATTITUDES AND SELF-EFFICACY

Jillian A. Joyce

119 Pages

Despite the growing number of students with disabilities in the university setting, few resources are offered to teach instructors about specific disabilities or provide direction for how to accommodate these students. This study used quantitative and qualitative methods to examine the influence of disability accommodation training on basic communication course instructors' attitudes and self-efficacy regarding students with disabilities. The training used attribution theory as a lens to specifically focus on stuttering, a disability that is often stigmatized and uniquely affects the basic communication course classroom. I gathered pre-test and posttest data from 12 basic course instructors who attended the training session and posttest responses from 28 basic course instructors who did not. Additionally, I examined responses from three focus groups, totaling 13 instructors, to determine the perceptions that basic course instructors had about the training session. Results suggest that the training session was effective in increasing instructor self-efficacy and instructors are desirous of further training and resources to accommodate students with disabilities. Specific implications for educators and trainers, and proposals for future research are discussed in detail.

KEYWORDS: Stuttering, PWS, Attribution Theory, Attitudes, Self-Efficacy, Basic Communication Course 
“I DIDN'T EVEN THINK OF THIS”: EXAMINING THE INFLUENCE OF STUDENT DISABILITY ACCOMMODATION TRAINING ON BASIC COURSE INSTRUCTOR ATTITUDES AND SELF-EFFICACY

JILLIAN A. JOYCE

A Thesis Submitted in Partial Fulfillment of the Requirements for the Degree of MASTER OF SCIENCE

School of Communication ILLINOIS STATE UNIVERSITY 
(C) 2017 Jillian A. Joyce 
“I DIDN'T EVEN THINK OF THIS”: EXAMINING THE INFLUENCE OF STUDENT DISABILITY ACCOMMODATION TRAINING ON BASIC COURSE INSTRUCTOR ATTITUDES AND SELF-EFFICACY

JILLIAN A. JOYCE

COMMITTEE MEMBERS:

Cheri J. Simonds, Chair

John Hooker

Lance Lippert 


\section{ACKNOWLEDGMENTS}

I would first like to express my immense gratitude to my parents, family, friends, and loved ones for their continual, incredible support. Your love, prayers, and words of encouragement were invaluable during this process and continue to be a source of strength and joy to me. I am grateful to know such excellent cheerleaders.

Secondly, I would like to thank Dr. Cheri Simonds for her constant dedication and steadfast support on this project. I came to her with an inkling of an idea, and not only did she let me run with it, but she nurtured, challenged, and developed that idea with me into what it is today. I am honored to work with a mentor who shares my passion for creating classroom environments that are student-centered.

Next, I would like to thank Dr. Hooker and Dr. Lippert for their guidance and insight. Your advice and directions throughout the stages of this project were priceless. Additionally, I owe a special thank you to Rene McClure and Sarah Metivier for dedicating their time to meet with me about this project and their willingness to be an integral part of training instructors how to accommodate students with disabilities. This project was successful because of each of you.

Finally, I would like to thank the young man whose story inspired my journey with this thesis. Thank you for sharing your experience in the basic course classroom and opening my eyes to the experiences of students who stutter. My goal is that this thesis serves as a foundation to prepare future generations of teachers for how to successfully welcome and accommodate students with disabilities in their classrooms.

J. A. J. 


\section{CONTENTS}

Page

ACKNOWLEDGMENTS

CONTENTS

CHAPTER

I. THE PROBLEM AND ITS BACKGROUND 1

Statement of the Problem 3

Purpose of the Study $\quad 5$

Significance of the Study $\quad 6$

$\begin{array}{ll}\text { Conclusion } & 6\end{array}$

$\begin{array}{lc}\text { II. LITERATURE REVIEW } & 8\end{array}$

$\begin{array}{ll}\text { The Causes and Effects of Stuttering } & 8\end{array}$

$\begin{array}{lr}\text { Defining Stuttering } & 9\end{array}$

$\begin{array}{ll}\text { Causes of Stuttering } & 10\end{array}$

Effects of Stuttering $\quad 11$

Federal Legislation, Higher Education, and Individuals with Disabilities 15

Section 504 of the Rehabilitation Act of $1973 \quad 16$

$\begin{array}{ll}\text { Americans with Disabilities Act of } 1990 & 17\end{array}$

Individuals with Disabilities Education Act 18

The Influence of the Basic Communication Course 19

Defining the Basic Communication Course $\quad 20$

Ubiquity of the Basic Communication Course $\quad 21$

Value of the Basic Communication Course $\quad 22$

The Basic Communication Course and Special Populations 24

$\begin{array}{ll}\text { Attribution Theory } & 26\end{array}$

$\begin{array}{ll}\text { Defining Attribution Theory } & 26\end{array}$

Attribution Theory and Students with Disabilities 28

Knowledge about Stuttering $\quad 29$

Attitudes about PWS 31 
Attitudes about PWS

Attitude and Familiarity with PWS

Attitude and Disability Training

Self-Efficacy and PWS

Defining Self-Efficacy

Self-Efficacy and Disability Training

Current Study, Hypothesis, and Research Questions

Conclusion

III. METHODS

Training and Development

Description of the ADDIE Model

Role of the Trainer

Description of the Current Training Development

Quantitative Research Methodology

Participants

Procedure for Participants

Group 1

Group 2

Instrument

Procedure for Scales

Qualitative Research Methodology 55

Participants $\quad 55$

Data Collection $\quad 55$

Procedure $\quad 56$

$\begin{array}{ll}\text { Data Analysis } & 57\end{array}$

$\begin{array}{lc}\text { IV. RESULTS } & 58\end{array}$

Quantitative Results $\quad 58$

Attribution Theory and Attitude $(\mathrm{H}) \quad 58$

Attitude Toward PWS Between Trained and Non-Trained Groups $\left(\mathrm{RQ}_{1 \mathrm{a}}\right) \quad 59$

Self-Efficacy Between Trained and Non-Trained Groups (RQ $\left.\mathrm{R}_{1 \mathrm{~b}}\right)$

Attitudes and Prior Experience $\left(\mathrm{RQ}_{2}\right) \quad 59$ 
Training Effect in Attitudes $\left(\mathrm{RQ}_{3 \mathrm{a}}\right)$

Training Effect in Self-Efficacy $\left(\mathrm{RQ}_{3 \mathrm{~b}}\right) \quad 60$

$\begin{array}{ll}\text { Qualitative Results } & 61\end{array}$

$\begin{array}{ll}\text { Self-Perception } & 61\end{array}$

Increased Self-Efficacy 61

Feelings of Inadequacy $\quad 65$

$\begin{array}{ll}\text { Student-Perception } & 66\end{array}$

Increased Empathy and Understanding 66

$\begin{array}{ll}\text { Future Concern } & 68\end{array}$

$\begin{array}{ll}\text { Logistical-Perception } & 68\end{array}$

Desiring Specific Resources $\quad 68$

Desiring Extended Time $\quad 69$

Valuing Expert Insight $\quad 70$

$\begin{array}{ll}\text { Conclusion } & 71\end{array}$

$\begin{array}{ll}\text { V. DISCUSSION } & 72\end{array}$

$\begin{array}{ll}\text { Summary of Findings } & 73\end{array}$

Quantitative Analysis $\quad 73$

$\begin{array}{ll}\text { Qualitative Analysis } & 75\end{array}$

$\begin{array}{ll}\text { Strengths and Limitations } & 79\end{array}$

$\begin{array}{lr}\text { Implications } & 82\end{array}$

Implications for Educators $\quad 82$

Implications for Training $\quad 83$

Implications for Future Research $\quad 85$

$\begin{array}{lr}\text { Conclusion } & 86\end{array}$

$\begin{array}{lr}\text { REFERENCES } & 88\end{array}$

APPENDIX A: TRAINING GOAL, OUTCOMES, AND OBJECTIVES 106

$\begin{array}{ll}\text { APPENDIX B: SURVEY QUESTIONNAIRE } & 110\end{array}$ 


\section{CHAPTER I}

\section{THE PROBLEM AND ITS BACKGROUND}

In November 2015, I attended a conference session with a friend on a whim. It was earlier than I like to be up, but she seemed interested in the topic, so I decided to go. The conversation was about accommodating students who stutter in the university classroom. After listening to several presentations, I was especially struck by a young man who was in his junior year of college. He spoke with a pronounced stutter and explained what his experience had been like during his freshman year public speaking class. He commented on his uncertainty about whether his peers would accept him, he described his fear of having to complete specific oral assignments, and he talked about the thankfulness he had for the teacher who worked with him to develop specific accommodations that allowed him to not only pass the class successfully, but enjoy it.

As a university instructor of the basic communication course, my mind raced after this session. How would I accommodate a student who stuttered in my class? What do I know about stuttering? More than that, what do I know about the logistics of accommodating a student with any disability within the university setting? I realized that although I had received helpful training in how to assess student assignments, engage in classroom management strategies, and develop my own "teaching style," the training I had received about accommodating students with disabilities was virtually limited to directions about where the student disability office was located in our building. It dawned on me that if I had a student who stuttered in my classroom, I would have no idea about what my legal obligations for accommodation would be or how I could successfully accommodate a student with a communicative disability in a class that requires public speaking as a main component for passing the course. 
This study was born out of my own interest and desire to serve my students well. I found my lack of knowledge about 1) the causes and effects of stuttering and 2) the implications that a communicative disability would have on the basic communication course alarming. As a teacher, it is my goal to make the basic communication course as comfortable and encouraging an environment for students as possible, especially because many of them take the course as part of their general education requirement and express to me their deep-seated fear of speaking in front of their peers. For me, being prepared to adjust elements of the course for students who require accommodation is a part of creating a successful classroom environment. When I first started exploring the research on stuttering and student accommodations, I found that many stories were not as uplifting as the one I had heard in November. Students seemed discouraged by their instructors' lack of understanding about stuttering and their willingness to provide accommodations.

While conducting my own research about stuttering and student accommodations, I realized that other instructors could likely benefit from this information as well. The following year was spent researching, interviewing, and developing a training session for incoming Graduate Teaching Assistants (GTAs) who would teach the basic communication course. The basic course serves as fertile ground for this type of training because of the public speaking requirement. At my university, students are required to present three substantive speeches in a face-to-face setting. The training session examined stuttering as a disability that would uniquely influence the public speaking course, and then discussed student accommodations generally. The training incorporated group discussion, media examples, and testimonies from the experts I had interviewed. To explore instructors' attitudes regarding students who stutter, perceptions about their own sense of self-efficacy in accommodating these students, and their perceptions of the 
training course, I gathered quantitative data from pretest and posttests, and qualitative data by conducting focus groups with participants and coding for themes. The goal of this thesis is to shed light on the experiences and needs of basic communication course instructors, specifically highlighting the necessity for further training about how to accommodate students with disabilities in their classrooms.

\section{Statement of the Problem}

In the United States, the requirement for public speaking in educational settings is rising (Arnold, Li, \& Goltl, 2015). In grade school and high school classes, the Common Core Standards Initiative charges students to "use appropriate eye contact, adequate volume, and clear pronunciation" (“Common Core State Standards Initiative”, 2016, para. 8) and many colleges and universities require all students to take a basic communication course, regardless of their major. While teachers design these courses to prepare and equip students for higher education and future careers, they also have the potential to negatively affect students with disabilities, particularly students who stutter. Stuttering is a communicative disability that affects 70 million people worldwide, occurring four times more often in males than females ("The Stuttering Foundation", 2017).

This study used attribution theory as a lens to examine the attitudes basic communication course instructors at the university level have about people who stutter (PWS) and the attributions they make about students who stutter. Attribution theory explains that people attempt to determine the cause of others' behavior by inferring if the root is internal or external, stable, and/or controllable (Weiner, 1985). Weiner (1985) notes that when a negative behavior is seen as controllable or internal, the person committing the behavior is more likely to be blamed for the behavior, and also experience stigmatization from others. According to the current literature on 
attitudes about PWS, people who perceive that stuttering stems from a biological cause instead of a psychological cause tend to have more positive attitudes toward PWS (Boyle, 2016). Additionally, there is literature to suggest that people who are familiar with PWS have more positive attitudes about people who stutter (Boyle, 2016; Yeakle \& Cooper, 1986) and teachers who have a higher sense of self-efficacy in the classroom are more positive about including students with disabilities (Brady \& Woolfson, 2008). Unfortunately, however, the vast majority of research concerning the perceptions of fluent speakers on PWS identify that fluent speakers often view PWS as “shy” (Yeakle \& Cooper, 1986), “annoying” (Hughes, Gabel, Irani, \& Schlagheck, 2010b), "unattractive” (Van Borsel, Brepoels, \& De Coene, 2011) and "mentally deficient" (Johnson, 2008).

Stuttering is a unique disability because all fluent speakers experience moments of dysfluency. With other disabilities, "able-bodied" individuals rarely experience symptoms of the disability. For example, most people do not experience moments of blindness or deafness. Whaley and Langlois (1996) note that it is perhaps this differentiation that influences the attitudes of fluent speakers. They state that perhaps because "all fluent speakers have dysfluencies at one time or another under stressful conditions, they may attribute the feelings or responses they themselves experience during these circumstances (e.g., nervousness, tension, embarrassment) to those who stutter during their dysfluent bouts" (p. 64).

Several studies have been dedicated to the perceptions of certain groups about people who stutter, including parents of PWS (Al-Khaledi, Lincoln, McCabe, Packman, \& Alshatti, 2009), primary and secondary school teachers (Abdalla \& St. Louis, 2012; Brady \& Woolfson, 2008; Marshall, Ralph, \& Palmer, 2002; Vaz et al., 2015), college instructors (Daniels, Panico, \& Sudholt, 2011) and university students (Hughes, Gabel, Irani, \& Schlagheck, 2010a; Hughes, 
Gabel, Irani, \& Schlagheck, 2010b). However, no study, to my knowledge, has focused specifically on the attitudes and attributions made by instructors of the basic communication course at the university level about students who stutter. This gap in the literature is concerning as many universities require their students to take at least one basic oral communication course (Mottet, 2006) and the majority of both two-and four-year universities utilize the public speaking model in the basic course (Morreale, Myers, Backlund, \& Simonds, 2016). While training in disability accommodation can help teachers experience higher levels of self-efficacy (Gotshall \& Stefanou, 2011) and better meet the needs of their students (Kosko \& Wilkins, 2009), teachers are rarely provided with instruction in how to interact with and accommodate students with disabilities (DeSimone \& Parmar, 2006).

\section{Purpose of the Study}

The purpose of this thesis is to examine the effect of a training session devoted to accommodating students with disabilities, including the communicative disability of stuttering. This training was presented to incoming Graduate Teaching Assistants who are the sole instructors of the basic communication course they teach. This study begins by examining the literature on stuttering, as well literature concerning the basic course, self-efficacy, and training and development. This study employs both quantitative and qualitative methods to assess the knowledge participants have about stuttering, their attitudes regarding PWS, their self-efficacy in interacting with and accommodating PWS, and their perceptions about the training session. This study will help basic course directors (and hopefully directors of other programs) to utilize training methods to proactively prepare instructors in how to best serve and accommodate students in their classes with disabilities. Further, it will help scholars, Speech Language Pathologists, and disability service offices to understand how basic course instructors perceive 
PWS and create stronger partnerships between programs that seek to assist students with disabilities in the university system.

\section{Significance of the Study}

The National Center for Education Statistics (NCES) found that in 2012 that approximately $11 \%$ of students enrolled in postsecondary education have a disability (NCES,

n.d.). Even though students with disabilities are more likely to attain positive professional outcomes after graduation than their non-disabled peers ("National Council on Disability," 2003), students with disabilities often face significant challenges within the university system, including high dropout rates (Hartley, 2010), course failure (Sanford et al., 2011), and difficulties in their relationships with instructors and peers (Adriaensens, Beyers, \& Struyf, 2015; Butler, 2013; Klompas \& Ross, 2004). One issue facing students with disabilities is that instructors and professors are often unaware of how to accommodate these students (Daniels et al., 2011). As improved attitudes and increased self-efficacy can benefit student learning, it is therefore necessary to not only train instructors on how to accommodate students with disabilities, but to understand their perceptions of these students.

\section{Conclusion}

This chapter presented my own personal interest in this topic, and provided a platform concerning the need for disability accommodation training in higher education, specifically in the basic communication course. This introduction highlights the experience PWS often have when interacting with fluent speakers, and calls attention to the necessity of addressing the knowledge, attitudes, and levels of self-efficacy basic course instructors have regarding PWS. Additionally, the purpose of this study is to evaluate the training session about student accommodations to make valuable adjustments in the future. This study will help bolster and 
expand the current training practices in the basic communication course, and will help construct bridges between key stakeholders, both within and outside the university setting, who want to create academic environments that successfully accommodate students. The next chapter provides the groundwork for a discussion about stuttering, looks at the role of the basic course in higher education, and the influence of attitudes, self-efficacy, and training. It also presents the theoretical framework that forms the basis of this study. 


\section{CHAPTER II}

\section{LITERATURE REVIEW}

As this study focuses on PWS, it is necessary in this chapter to first offer a description about stuttering and then describe the literature about how stuttering influences the lives of PWS. The role that federal legislation has played in the modern disability rights movement is also important to understand to realize the responsibility of instructors in higher education institutions. Since stuttering is a disability that can uniquely influence the basic communication course, this chapter will explore the role and value of the course in higher education. PWS should not be barred or excused from the course because of their stutter; instead appropriate accommodations should be provided to allow students who stutter an equal footing in the class with their fluent peers. While knowing how to accommodate PWS is an important element in instructor self-efficacy, it is not the only important factor. Instructor attitudes and knowledge about PWS must also be assessed. The theoretical framework of attribution theory helps scholars make sense of the stigmatizations that various groups experience. While no available research has examined basic communication course instructors' perception of stuttering through the lens of attribution theory, the use of theory in examining other stigmatized groups makes it a valuable and appropriate lens for the current study.

\section{The Causes and Effects of Stuttering}

In everyday vernacular, people often use the term "stuttering" to describe a moment of verbal dysfluency: a brief stammer in answering a difficult question, a moment of repetition while saying a challenging word, or an instance of verbal fillers (such as "um" or "uh") when attempting to gather thoughts. As a basic communication course instructor, I routinely hear students say, "When I feel nervous to speak in front of others, I stutter." Stuttering, however, is 
not the same thing as general verbal dysfluency. While students may stumble over their words when they experience psychological discomfort, stuttering is a communication disorder that affects more than 70 million people worldwide ("The Stuttering Foundation," 2017). Rieber and Wollock (1977) describe stuttering as "one of the best known yet least understood disorders of communication" (p. 3).

\section{Defining Stuttering}

Stuttering is defined as "a disruption in the fluency of verbal expression characterized by involuntary, audible or silent, repetitions or prolongations of sounds or syllables" (Büchel \& Sommer, 2004, p. 159) and may be accompanied by other movements, known as secondary or accessory behaviors, such as closing of eyes or lips, tensing jaw or cheeks, or tapping fingers or feet (Scott, Guitar, \& Chemla, 2010). Büchel and Sommer (2004) note that, officially, stuttering is "a symptom, not a disease, but the term stuttering usually refers to both the disorder and symptom" (p. 159). Stuttering is typically divided into three main patterns: repetitions of sounds and syllables (li-li-li-like this), sound prolongations (11ll1llike this), and blocks, which are periods of silence while the PWS attempts to make the sound. This period of silence is often followed by a quick burst of sound once the PWS is finally able to say the word (Scott et al., 2010). According to the World Health Organizations' (WHO) International Classification of Functioning, Disability, and Health (ICF; WHO, 2001), disabilities restrict activities and participation, which for PWS could include limitations in education, employment, social interactions, and with technology, such as a telephone (Yaruss \& Quesal, 2004).

It is important to note that stuttering can be categorized as either persistent developmental stuttering (PDS) or acquired stuttering. PDS is the most common type of stuttering and typically arises in young children between the ages of 3-4 years old, and affects up to $20 \%$ of all children 
(Drayna \& Kang, 2011). Approximately $80 \%$ of all children who stutter recover and do not stutter after puberty, resulting in PDS in about $1 \%$ of the adult population (Büchel \& Sommer, 2004). Stuttering also affects the sexes differently; males are four times more likely to stutter than females and females are more likely to recover (Drayna \& Kang, 2011). Acquired, or neurogenic, stuttering is rarer and occurs after significant brain damage, such as in the case of a stroke, head trauma, or an intracerebral hemorrhage (Büchel \& Sommer, 2004). Throughout this study, "stuttering" will exclusively refer to PDS.

\section{Causes of Stuttering}

While there are many factors that may contribute the development of stuttering, the exact cause of the disorder is unknown (Hulit, 2004). Throughout the centuries, the theories on what causes stuttering have widely evolved. In ancient Greece, stuttering was thought to stem from a dry tongue (Büchel \& Sommer, 2004) while during the Renaissance stuttering was attributed to humidity, as well as dental problems or issues with the muscles of the mouth (Rieber \& Wollock, 1977). In the 1800 s, stuttering was believed to be an effect of oral abnormalities, leading to elaborate surgeries, which often ended in mutilation and further disabilities (Büchel \& Sommer, 2004). In the $20^{\text {th }}$ century, the origins of stuttering shifted away from a physical examination to a psychological lens. External factors, such as negative responses from a parent during a child's developmental speaking years, were thought to cause stuttering (Snyder, 1977).

Today, four factors are believed to most likely contribute to developmental stuttering: genetics, child development, neurophysiology, and family dynamics. Approximately $60 \%$ of individuals who stutter also have a family member who stutters, and children who have other developmental delays may be more likely to stutter. Additionally, parental pressure and fastpaced routines can contribute to stuttering ("The Stuttering Foundation", 2017). Büchel and 
Sommer (2004) note that brain activity seems to differ in individuals who stutter versus individuals who are fluent. In PWS, the left hemisphere of the brain is more active during stuttered speech, while activity in the right hemisphere is correlated with fluent speech. In individuals who stutter, the right hemisphere seems to be hyperactive. The authors explain that, "Whereas fluent controls activated left frontal brain areas involved in language planning before central areas involved in speech execution [in fluent speakers], this pattern was absent, even reversed, in stutterers” (p. 162). Büchel and Sommer (2004) also note that decreased white matter in the brain may indicate disturbed signal transmission, impairing fluent speech production.

Stuttering can also be cyclical, varying in frequency and severity throughout an individual's life (Scott et al., 2010). For example, a PWS may not stutter at all when speaking to friends, but may stutter on the phone or when reading aloud. Similarly, the content of the speech or the audience may influence a stutter. The National Stuttering Association (2017) states that a PWS may be more likely to stutter when saying his/her name or speaking to an authority figure. Individuals who stutter may also be more likely to stutter due to external factors such as fatigue or stress, of if they feel obligated to hide their stutter.

\section{Effects of Stuttering}

While individuals who stutter are not less intelligent than individuals who are fluent (Beech \& Fransella, 1968; Bloodstein, 1993), depictions of PWS in the media are traditionally negative and often pander 'to the public's basic ideas of stuttering and thus have been stereotypical, unrealistic, and at times even derogatory" (Johnson, 2008, p. 246). Johnson (2008) explains that stuttering in the media is often depicted as a personality flaw or intellectual weakness, and characters that stutter are rarely cast in the role of the hero. Instead characters that 
stutter are more often cast as villains (such as the Footpath Killer in CBS's Criminal Minds), weak-willed pushovers (such as Ken Pile in A Fish Called Wanda or Professor Quirrell in Harry Potter and the Sorcerer's Stone) or the target of jokes (including Warner Brothers cartoon character, Porky Pig), and are only able to lose their stutter when they "toughen up" (Johnson, 2008, p. 250) to their opponents. As negative or inaccurate perceptions can become a part of the social identity of PWS (Blood, Blood, Tellis \& Gabel, 2003) it is important to examine the effect that stuttering can have on the life of PWS.

While there is not a personality character structure that defines all people who stutter (Sermas \& Cox, 1982; Silverman, 2004), significant research has been devoted to the effect that a communicative disability may have in lives of PWS, including how a stutter effects the realms of education (Butler, 2013; Klein \& Hood, 2004; Klompas \& Ross, 2004; Meredith, Packman, \& Marks, 2012), social life, including relationships with family, friends, and romantic partners (Adriaensens et al., 2015; Blood \& Blood, 2004; Blood, Blood, Tellis, \& Gabel, 2003; Craig, Blumgart, \& Tran, 2009; Klompas \& Ross; 2004) employment (Klein \& Hood, 2004; Klompas \& Ross; 2004; Meredith et al., 2012; Silverman \& Paynter, 1990; Whaley \& Langlois, 1996), self-esteem and identity beliefs (Adriaensens et al., 2015; Blood \& Blood, 2004; Blood, Blood, Tellis, \& Gabel, 2001; Blood et al., 2003; Bray, Kehle, Lawless, \& Theodore, 2003; Klompas \& Ross; 2004) and anxiety, depression, and social phobia (Craig et al., 2009; Craig \& Tran, 2014; Ezrati-Vinacour \& Levin, 2004; Iverach \& Rappe, 2014; Kraaimaat, Vanryckeghem, \& Van Dam-Baggen, 2002; Meredith et al., 2012; Tran, Blumgart, \& Craig, 2011; Whaley \& Langlois, 1996).

Blood et al. (2003) examined the self-esteem, perceived stigma, and disclosure practices of 48 adolescents who stutter. They found that the majority of participants (85\%) indicated that 
they had positive self-esteem and more than $60 \%$ reported that their stutter did not influence their social lives (such as making friends, going on dates or to parties, or being liked by their peers). They also found that older adolescents (ages 16-18) perceived their stutter as less stigmatizing than adolescents between the ages of 13 and 15 . Additionally, $95 \%$ of the older adolescents indicated that all their friends knew they stutter, while only $73 \%$ of the younger adolescents reported that all their friends knew they stutter. Blood et al. (2003) found that younger adolescents are more likely to try and conceal their stutter, and may use more avoidance techniques. Similarly, in their qualitative study on the life experiences of PWS, Klompas and Ross (2004) interviewed 16 adults about how their stutter influenced their education, social life, employment, relationships, and identity, and found that the majority of their participants stated that their stutter had not negatively influenced their ability to establish friendships, nor had it influenced family or marital relationships, but participants did note that people often reacted negatively to their stuttering. This negative reaction from others may be a primary influencer in the literature regarding anxiety, depression, and social phobia in PWS. Klompas and Ross (2004) found that many participants described feelings of frustration and anger in regard to their stutter. Craig and Tran (2015) found that up to $40 \%$ of PWS are at risk of developing "clinically elevated social anxiety" (p. 37) while Kraaimaat et al. (2002) found that approximately 50\% of PWS in their study were highly socially anxious. Social anxiety can be defined as an "anxiety disorder characterized by significant fear of humiliation, embarrassment, and negative evaluation in social or performance-based situations" (Iverach \& Rapee, 2014, p. 69). While PWS may not experience social anxiety around friends or family, certain social situations such as talking on the phone (Craig \& Tran, 2015; Silverman, 2004), speaking during meetings or group discussions (Blood \& Blood, 2004; Blood et al., 2001; Craig \& Tran, 2015) or during public speaking (Blood 
\& Blood, 2004) may elicit a more negative response from PWS compared to their fluent peers. Kalinowski, Lerman, and Watt (1987), however, found that PWS did not necessarily perceive themselves differently from their fluent peers. Participants who stutter described themselves just as "open," "secure," "talkative," and "friendly," as the fluent participants in the study. Interestingly, when asked to rate the other group, PWS perceived fluent speakers as more "calm," "friendly," and "secure" than fluent speakers who gave lower ratings to PWS on these same traits.

A significant effect that stuttering may have of the life of PWS is its influence in academic and vocational settings. Adriaensens et al. (2015) found that PWS have more negative scores in perceived school competence, and Meredith et al. (2012) found that stuttering severity influences likelihood of high school graduation; the more severe an individual's stutter, the less likely they were to complete high school. Klompas and Ross (2004) offer a potential explanation for why students may not complete high school; participants in their study stated that their stutter had influenced their academic performance and relationships with teachers and classmates, specifically because of "difficulties with oral presentations, lack of understanding on the part of some teachers, and teasing by some classmates" (p. 297).

PWS in the workplace reported various experiences with how their stutter influenced their career. Klein and Hood (2004) found in their study of 232 PWS than $71 \%$ of participants indicated that a stutter would decrease an individual's chances of being hired and $80 \%$ agreed that if a PWS and a fluent speaker were both equally qualified for a position, the employer would view the non-stuttering candidate more favorably. While only $36 \%$ indicated that their stutter interfered with their job performance, $69 \%$ stated that stuttering had interfered with their job performance at some point. Klompas and Ross (2004) found that about half of their participants 
stated that their stutter did not affect their performance at work; however, most believed their chances of receiving a promotion were hindered by their stutter. Klein and Hood (2004) reported similar findings. They found that $70 \%$ stated that a stutter would interfere with the possibility of receiving a promotion at work. It is interesting to note that $50 \%$ of the participants in Klein and Hood's (2004) study sought employment that required little speaking, and 21\% had actually turned down a promotion or a new job because of their stutter. They also found that females who stutter were less likely than males who stutter to view their dysfluency as a handicap and that non-Caucasians viewed stuttering to have a greater negative effect on their performance at work than Caucasians. Finally, the level of education of the participants influenced how they perceived their stutter at work. Those who had received more education found their stutter to be less of an issue (Klein \& Hood, 2004). This information is valuable to educators, as the level of academic instruction PWS receive can have an influence on their future vocational success (Meredith et al., 2012). The following section will examine the influence of federal legislation on individuals with disabilities, as well as the relationship between students with disabilities and higher education institutions.

\section{Federal Legislation, Higher Education, and Individuals with Disabilities}

Several important pieces of legislation have been established to protect the rights of people with disabilities, specifically Section 504 of the Rehabilitation Act of 1973, the Americans with Disabilities Act (ADA) of 1990, and the Individuals with Disabilities Education Act (IDEA). These regulations help to define what qualifies as a "disability" and what is meant by "equal opportunity." These regulations ensure that individuals with disabilities are able to access buildings, programs, and services. 


\section{Section 504 of the Rehabilitation Act of 1973}

It is important to note that legislation regarding individuals with disabilities is relatively new. Nicastro (2000) explains that up until the mid-twentieth century, only two federal laws offered any protection for people with disabilities: The Social Security Act of 1935 and the LaFollette-Barden Act of 1943. Both acts pertained to very specific audiences. For example, the Social Security Act of 1943 focused on "providing medical and therapeutic services for 'crippled' children” (Nicastro, 2000, p. 357), while the LaFollette-Barden Act of 1943 offered services that would encourage employment for individuals older than 15 years old (Nicastro, 2000). While changes in the public education system in the early $20^{\text {th }}$ century, such as compulsory attendance laws, began to transform the educational opportunities allotted to students with disabilities, these students often still did not receive adequate education (Yell, Rogers, \& Rogers, 1998). Yell et al. (1998) explain that parents and student advocates began to use the courts to seek better educational opportunities for students with disabilities. Nicastro (2000) identifies that the momentum of the disability rights movement stemmed from the milestone decision of Brown v. Board of Education, the landmark case when the Supreme Court determined that racial segregation in schools was unconstitutional because "in the field of public education the doctrine of 'separate but equal' has no place" ("History - Brown v. Board of Education Re-enactment, n.d., para. 14). In this historic case, Black students were provided equal protection and due process under the Fourteenth Amendment (Kluger, 2004). This idea of equal protection for all people inspired the disabilities rights movement in modern society (Nicastro, 2000).

Section 504 of the Rehabilitation Act (Section 504), which was signed into law by President Nixon in 1973, states that, "No otherwise qualified handicapped individual in the 
United States...shall solely by reason of this handicap, be excluded from participation in, be denied the benefits of, or be subject to discrimination under any activity receiving federal financial assistance" (Section 504, 29 U.S.C. section 794(a)). The U.S. Department of Education (2015) explains that protections provided under Section 504 extend to public school districts, public colleges and universities, and any other local or state education agencies. To be protected under Section 504, a student must be determined to "(1) have a physical or mental impairment that substantially limits one or more major life activities; or (2) have a record of such an impairment; or (3) be regarded as having such an impairment" ("The Civil Rights of Students", 2015).

\section{Americans with Disabilities Act of 1990}

While the Rehabilitation Act of 1973 was an important step for individuals with disabilities, the law only provided protection to individuals who were employed by federal offices or received federal funding (Nicastro, 2000). On July 26, 1990, President George H. W. Bush signed the Americans with Disabilities Act (ADA) into law ("Introduction to the ADA", n.d.). The purpose of the ADA is to "provide a clear and comprehensive national mandate for the elimination of discrimination against individuals with disabilities" (42 U.S. Code $\S 12102$ ). The ADA expanded Section 504 by providing protection for workers with disabilities at companies of fifteen or more employees, to state and local governmental programs, and to private providers of public accommodations, including many private colleges and universities (Rothstein, 2015).

The ADA provides several legal rights for individuals with disabilities including the right to transportation, to enter a building, to acquire information from a website, to drink from a water fountain, and to receive reasonable accommodations allowing them to work (Fogliasso \& Hicks, 2012). These early roots of the modern disabilities rights movement provided a voice to 
people with disabilities, as well as a platform to define themselves. Eichhorn (1999) states that the "hallmark of the [disabilities rights] movement is the refusal of disabled people to be marginalized — that is, to be viewed as "the Other"-in a society dominated by non-disabled people" (pp.1409-1410.) Not only does disability legislation allow equal protection for individuals with disabilities, but also within the movement "disabled people have chosen to define themselves rather than to accept societal dictates regarding who they, as disabled people, should be" (Eichhorn, 1990, p. 1410). Eichhorn (1990) makes the case that "disabled" is a label that is socially constructed, arbitrary, and limits the view of what people "should" be able to do and how those things "should" be done. The main impetus of the ADA is to ensure that people with disabilities can fully participate in society (Nicastro, 2000). To qualify for protection under the ADA, an individual must prove that he/she has a disability (Nicastro, 2000). The definition of a disability is the same for the ADA as Section 504 (42 U.S. Code § 12102; Nicastro, 2000).

\section{Individuals with Disabilities Education Act}

The Education for All Handicapped Children Act of 1975, which was later renamed The Individuals with Disabilities Education Act (IDEA) (Krewson, 2016), seeks to "ensure disabled students receive the same opportunities as their nondisabled peers" (Beatty, 2013, p. 529). A main tenant of the IDEA is "free appropriate public education" (FAPE) for all students with disabilities (20 U.S. Code $\S 1412$ ). The provisions of the IDEA also provide regulations and mandates regarding the rights of children and parents to receive an individualized education program (IEP) (Beatty, 2013; 20 U.S. Code § 1412) and provide a process for parents and students to challenge placement changes (Beatty, 2013). Additionally, the IDEA requires "the child with a disability to be placed in the educational environment where he or she would attend were there no disability" (20 U.S.C. § 1412(a)(5)). Under some circumstances, this requirement 
compels mainstreaming, or the "placement of children with disabilities into the regular classroom with their non-disabled peers" (Krewson, 2016, p. 516.) Krewson (2016) explains that prior to IDEA, expulsion served as a primary way to remove children with disabilities from the classroom. Therefore, the IDEA also includes a stay-put provision to help provide safeguards for students and determine if the student's disruption in the classroom is a manifestation of the student's disability (Krewson, 2016).

While all postsecondary institutions are required to follow Section 504 and the ADA, postsecondary schools are not required to provide FAPE (U.S. Department of Education, 2011). Rather the U.S. Department of Education (2011) states that higher education institutions are required to provide "appropriate academic adjustments" to ensure that non-discrimination for students with disabilities (U.S. Department of Education, 2011; Zhang et al., 2010). Because colleges and universities must provide accommodations for students with disabilities, it is important to examine how students with disabilities may be influenced by specific courses, including general education requirements. The following section will examine a course that may require unique accommodations for PWS: the basic communication course.

\section{The Influence of the Basic Communication Course}

A critical lens has been used to study the basic communication course in many capacities, including examining the basic course as grounds for anti-racist pedagogical practices (Fotsch, 2008), critical communication pedagogy (Fasset \& Warren, 2008), and pedagogy designed to incorporate English language learner students (Hao, 2010). Research, however, has not focused on the gap in pedagogical training for basic communication instructors in accommodating students with disabilities, specifically disabilities that influence the public speaking component of the course. It is important to address this gap because of the influence that the basic 
communication course can have on student learning and the role that basic communication course plays in the general education system. Students who stutter can benefit from the course in the same way as any other student; however, instructors may struggle in knowing how to accommodate these students without proper training.

\section{Defining the Basic Communication Course}

The basic communication course can take many forms in the university setting. However, Morreale, Hanna, Berko, and Gibson (1999) define the course as "that communication course either required or recommended for a significant number of undergraduates; that course which the department has, or would recommend as a requirement for all or most undergraduates" (p. 3). Often, the course is taught in one of two ways: either as a public speaking course or as a hybrid (or survey of the discipline) course. The public speaking course emphasizes assignments that focus specifically on the creation and development of presentations, while the hybrid course combines public presentations with units on intrapersonal, interpersonal and/or group communication (Kramer \& Hinton, 1996). Morreale et al. (2016) found that the most popular approach to the basic communication course at both two- and four-year colleges is public speaking, followed by the hybrid course. In their data gathered in 2015, public speaking encompasses $66.7 \%$ of instruction at two-year schools, while the hybrid course covers $42.9 \%$. At four-year schools, public speaking encompasses $59.9 \%$ of instruction, while $26.9 \%$ use a hybrid course. In their study, approximately $12 \%$ of schools reported an alternative to one of these methods, such as an interpersonal communication course or a small group course. In the basic communication course, presenting speeches is a main component. Morreale, Worley, and Hugenberg (2010) found that the $43.4 \%$ of the two- and four-year universities in their study 
required one to three speeches during the course, $34.9 \%$ required four speeches, $14 \%$ required five speeches and 3.3\% (at four-year schools) required six to ten speeches.

\section{Ubiquity of the Basic Communication Course}

One reason why it is valuable to examine the basic communication course as a platform for disability training is because of the ubiquitous nature of the course across the country. Morreale, Hugenberg and Worley (2006) explain, "hundreds of thousands of college students enter a basic communication course classroom" (p. 415) on a daily basis. Students may take the course because they choose to, or may take the course as a part of a general education requirement. Morreale et al. (2016) found that the basic communication course is required in the general education program at most two- and four-year programs, with the requirement by twoyear schools being higher $(95.2 \%)$ than four-year universities $(77.2 \%)$. The push for the basic communication course in general education programs across the country has been underscored for more than a decade. The National Communication Association (NCA) emphasized the importance of the basic communication course in general education in its 1996 Policy Platform Statement on the Role of Communication Courses in General Education, where it "endorsed efforts on every campus to include oral communication instruction in general education programs" (Valenzano, 2013, p. 16). This resolution was revised in 2012 to reflect the newer general education initiatives (Simonds, Buckrop, Redmond, \& Hefferin, 2012) where communication knowledge and skills are championed.

At both two-and four-year universities, 80 to $100 \%$ of delivery occurs in the traditional classroom, as opposed to online or televised delivery. Morreale et al. (2010) also found that most universities do not have courses geared for special student populations, including non-native English speaking students, or students with high levels of communication apprehension, anxiety, 
or reticence. The authors did find that almost all two-year schools (94.9\%) and four-year schools (81\%) provide accommodations for students with disabilities, and that most of these universities offer individualized accommodations for students with disabilities based on recommendations from a disability services office. It is expected that all universities should provide accommodations for students with disabilities because of legal standards set forth by Section 504 of the Rehabilitation Act of 1973 and the Americans with Disabilities Act of 1990.

\section{Value of the Basic Communication Course}

The basic communication course has many functions, both for the field of communication and the students enrolled. Craig (2006) notes that very few departments have the luxury of having a course that is required for all students entering a university and Valenzano (2013) describes the basic course as "a central component to most communication departments across the country" (p. 13). The basic course functions as an introduction for most students to the field of communication and serves the vital purpose of recruiting communication majors and minors (Morreale et al., 2006). The course provides students with necessary communication skills instruction through oral communication (Hugenberg \& Moyer, 1997) and is perceived to be foundational to a well-rounded education (Morreale \& Pearson, 2008).

For students, the basic course provides fundamental skills for both achievement in academics and success in the post-graduate world. Morreale, Osborn, and Pearson (2000) note the benefits of the basic communication course include the development of the whole person, increased social and cultural global citizenship, and vocational and business success. Many studies have emphasized the value of the basic course in helping students prepare for future employment (Curtis, Winsor, \& Stephens, 1989; Hunt, Ekachai, Garard, \& Rust, 2001) by providing them with skills such as enhanced listening abilities (Housley Gaffney \& Frisby, 
2013), critical thinking skills (Hunt, Novak, Semlak \& Meyer, 2005), and public speaking skills (Verderber, 1991). While other courses may be able to boast about enhanced global citizenship or increased critical thinking, the communication skills that stem from a student's public speaking performance are often unique to the basic course. While most students face a level of anxiety, stress, and uncertainty when preparing to deliver a public speech in the basic communication course (Hodis \& Hodis, 2013), basic course instructors can provide the opportunity to facilitate social support and praise from peers, develop a classroom environment centered around communicating mutual respect, and the offer occasions for students to develop a sense of connectedness with their classmates (Bingham, Carlson, Dwyer, \& Prisbell, 2009). Developing these essential communication skills is vital if students are to become effective communicators (Hodis \& Hodis, 2013; Hunt, Simonds, \& Simonds, 2009).

The skill of public speaking is an essential element in the 1993 National Education Goals Panel and the communication competencies developed by the United States Department of Labor (Newburger, 1994). According to these standards, students must be able to communicate effectively and have the ability to speak and listen well to accomplish work-related tasks. Dunbar, Brooks, and Kubicka-Miller (2006) note that the goal of teaching oral communication in higher education "is to prepare students to be more effective employees and responsible citizens" (p. 116). The NCA has identified several skills specifically related to public speaking that should be taught at the basic level, including speaking clearly and expressively, utilizing audience analysis, organizing ideas effectively, and providing thorough support for information (Dunbar et al., 2006). Additionally, NCA developed The Competent Speaker Speech Evaluation Form (“Assessing the Basic Course", n.d.), which includes measures that assess eight competencies encompassing vocal variety, pronunciation, articulation and grammar, and physical (or 
nonverbal) behaviors that support the verbal message. LeBlanc Farris, Houser, and Wotipka (2013) note that public speaking skills have climbed the ranks as one of the most desirable and necessary skills for students graduating from college to possess. In the basic communication course classroom, students have the ability to develop these important communication techniques and practice them in a safe environment. The security of this classroom can "create positive feelings about communicating in the future" (Dunbar et al., 2006, p. 117).

\section{The Basic Communication Course and Special Populations}

While there is a wide variety of research in accommodating students with disabilities in higher education in general, there is less data about how to accommodate students who fall outside of the "norm" in the basic communication course classroom. Research has been conducted on accommodating deaf students (Johnson, Pliner, \& Burkhart, 2002), utilizing universal design in classroom technology for students with disabilities (Stawser, Frisby, \& Kaufmann, 2017), and negotiating multicultural classrooms (Braithwaite \& Braithwaite, 1991). In my research, only one article has focused on students who stutter in the basic course classroom. Whaley and Langlois (1996) provide a thorough review of the literature concerning the nature of stuttering, the self-perception of people who stutter, attitudes about individuals who stutter, and strategies for communicating with people who stutter. While this information is appreciated, and needed in basic course dialogue, the article does not provide empirical data about how basic communication course instructors specifically view PWS or address concerns with how they should be trained to accommodate PWS.

To provide insight into the lived experience of PWS, Butler (2013) conducted interviews with PWS about their time in school. Participants ranged from 19 to 89 years of age, yet each generation had very similar experiences. Unfortunately, the stories were overwhelmingly 
negative. Participants noted that while several elements of the school day were challenging, experiences interacting with teachers proved to be the most difficult. Notably, participants described the lack of accommodation offered by teachers, even after the student requested it. Participants commented on the anxiety and fear they experienced in class because of the unaccommodating environment. Because these PWS were so focused on worrying if they would have to read out-loud or deliver impromptu speeches in front of the class, they were often too internally distracted to retain the teacher's lesson. Adolescents who stutter often experience higher levels of communication apprehension compared to adolescents who do not stutter, and perceive that they have poorer communication competence than their peers (Blood et al., 2001). Arnold et al. (2015) speculate that because teachers often attribute higher levels of communication apprehension with lower levels of communication competence, PWS may perceive these lower expectations from their teachers, resulting in a cyclical pattern of even more communication apprehension.

A lack of communication with the teacher during class was another theme Butler (2013) discovered. Participants described how "their educational experience was hampered by their inability to ask questions in class, and with no other mechanism being offered other than verbal communication" (p. 60). Students who stuttered were often placed in the back of the class to keep them from distracting the other students. Abdalla and St. Louis (2012) found similar responses from students who described interacting with teachers who would ignore the PWS's raised hands in class, or advise them to ask questions after the lesson or during a break, experiences which led to the students feeling marginalized. Because of these negative school experiences, many of the participants in Butler's (2013) study decided not to attend a university after graduating. Of the 38 participants in her study, five went on to a higher education setting 
where, "they enjoyed the relative anonymity afforded to them at university where the fear of speaking was reduced and they were 'better able to hide"” (p. 61). These PWS described purposefully missing classes where they had to give oral presentations, choosing to accept a lower grade instead. These behaviors are worrisome, especially as many basic courses require students to give speeches and the requirements for oral communication presentations in college courses become more demanding.

Basic communication course instructors are in a unique position to provide students with necessary communication skills for their future careers, and to create a classroom environment that allows students a safe and productive space to practice, critique, and hone their abilities. These skills are valuable to all students, including students who stutter. However, if basic course instructors have a negative view about students who stutter, or are unaware of how to adjust the classroom so that these students can be successful, there is a potential danger that students who stutter may be at a disadvantage. The following section will discuss how attribution theory can be used as a lens to examine why individuals, including instructors, may have certain beliefs and attitudes about PWS.

\section{Attribution Theory}

\section{Defining Attribution Theory}

Heider (1958) is widely regarded as the father of attribution theory. He argues that individuals routinely use common-sense psychology to negotiate their interactions with others. As Heider (1958) explains, “in everyday life we form ideas about other people and about social situations. We interpret other people's actions and we predict what they will do under certain circumstances" (p. 5). Attribution theory states that individuals assign either internal or external causes as the root of another's behavior (Whitehead, 2014). When an action or behavior is 
credited to an individual's personality, character, or attitude, an internal (or dispositional) attribution has been made. Conversely, when an action or behavior is credited to environmental factors that are outside of an individual's control, an external attribution is made (Joslyn \& Haider-Markel, 2013).

Weiner (1985) extended Heider's work by specifying three dimensions of causality: locus, stability, and controllability. Locus explains the internality or externality of an individual's behaviors. Stability, on the other hand, refers to the consistency of a behavior. Weiner (1985) gives an example of stability when he elaborates on the difference between ability, effort, task difficulty and luck; he states, "ability [is] classified as internal and stable, effort as internal and unstable, task difficulty [is] thought to be external and stable, and luck [is] considered external and unstable" (p. 551). Control is described as the intent with which an individual commits an action, or the level of power a person has over his/her behavior. The literature on attribution theory shows that individuals are more willing to exhibit helping behaviors when they perceive that the source of another's action or behavior is external and uncontrollable, while negative behaviors that are seen as internal and controllable often incite blame (e.g., Boyle, 2014; Boyle, 2016; Weiner, 1985). Attribution theory also accounts for the fundamental attribution error, which states that individuals tend to overemphasize the likelihood of an internal source of another's behavior, and minimize the potential of external or environmental factors (Joslyn \& Haider-Markel, 2013). Attribution theory has been used to examine a variety of stigmatized groups, including people with diabetes (Vishwanath, 2014), people in poverty (Osborne \& Weiner, 2015), and individuals in same-sex marriages (Whitehead, 2014). 


\section{Attribution Theory and Students with Disabilities}

People who stutter (PWS) have also been studied as a stigmatized group through the lens of attribution theory. Boyle (2016) found in a study of 165 university students that those who viewed stuttering as controllable reported higher levels of blame and anger toward PWS than those who viewed stuttering as resulting from a biological (or uncontrollable) cause. Similarly, a study of 330 school-based speech-language pathologists showed that perceptions of controllability were significantly related to higher levels of blaming students for stuttering, as well as decreased sympathy and decreased willingness to help the student (Boyle, 2014). Higher levels of blame were not only linked to higher perceived controllability, but also to a greater dislike of students who stutter and more beliefs about negative stereotypes. Conversely, participants who attributed uncontrollable, biological causes for stuttering reported higher levels of sympathy for PWS.

Brady and Woolfson (2008) help explain why studying the process in which teachers make attributions about their students is vital to the potential success (or failure) of students. The researchers examined responses from 118 primary school teachers in Scotland regarding experiences teaching children with learning disabilities, teaching efficacy, and attributions teachers make about children who experience learning difficulties. Results indicated that teachers who viewed disabilities as stable (or consistent and unlikely to change) tend to have lower expectations about the future success of students with learning difficulties. The authors stated that lower expectations could influence the types of goals teachers set for their students as well as their belief that a student will be able to achieve these goals. Additionally, teachers were more willing to help students in the classroom if they viewed the disability as uncontrollable. Teachers also may be more inclined to attribute student failure or low achievement to causal, student- 
related attributions (Jager \& Denessen, 2015), rather than external factors. These findings indicate that teachers are more prone to believe that student failure is the fault of the student, rather than the fault of the environment (such as a classroom or a teacher's teaching style.) Further studies have shown that teachers are often more willing to include students with physical disabilities as opposed to cognitive or behavioral disabilities (Soodak, Podell, \& Lehman, 1998) and students with non-visible disabilities face the extra challenge of "convincing" teachers of their disability. Beilke and Yssel (1999) aptly explain, "Easily verifiable, physical disabilities do not place faculty in the position of compromising academic integrity or being duped into 'believing' students who only claim to need special assistance" (p. 1). Findings like this are discouraging as misunderstandings about the causes and controllability of stuttering has the potential to lead fluent individuals to assume that stuttering has a psychological, instead of a biological, root, and can therefore be "treated" as a psychological issue. Therefore, it is important to examine what teachers know about stuttering and their attitudes regarding PWS.

\section{Knowledge about Stuttering}

One hurdle for PWS is a lack of knowledge about the causes and effects of stuttering in the general population. In a study of Arab school teachers' beliefs regarding stuttering, Abdalla and St. Louis (2012) polled 471 in-service and pre-service public school teachers in Kuwait. Using the Public Opinion Survey of Human Attributes-Stuttering (POSHA-S), the authors found that most of these teachers held stereotypical views about stutterers, including the belief that PWS are nervous and shy or fearful. While $72.2 \%$ of respondents stated that they do not believe PWS have a lower than average IQ, $42.7 \%$ indicated that they do not believe that a stutterer can do any job they want. This belief echoed an earlier study that found $50 \%$ of the Arab parents surveyed believed PWS should not work in influential jobs, such as politicians, doctors, lawyers, 
and teachers (Al-Khaledi et al., 2009). More than half of the teachers said that they would feel comfortable interacting with a PWS, yet $63 \%$ indicated that they would feel pity for the person. Interestingly, in response to a survey item asking teachers to indicate if they believe PWS have themselves to blame for their disability, $65 \%$ answered 'yes' or 'unsure'. These responses are concerning, as teachers who have inaccurate beliefs about PWS may fail to proactively include students who stutter in their classroom (Arnold et al., 2015).

Even teachers who want to engage PWS in the classroom may lack the knowledge or resources about how to do so. They also may believe that their actions are benefitting a student who stutters, when the opposite may be true. Abdalla and St. Louis (2012) found that $89 \%$ of the teachers stated that they would not feel impatient with a PWS and would be willing to wait while the person stutters; however, $60.3 \%$ said that they would fill in the person's words. Abdalla and St. Louis hypothesize that this "urge to fill in may not have stemmed from impatience per se but might be an action taken to help the person become "unstuck"' (p. 65). This good-will gesture is often unappreciated by PWS. Several studies (e.g., Butler, 2013; Daniels et al., 2011; Klompas \& Ross, 2004) have found that PWS emphasize their desire to finish their own sentences and interact with a patient listener.

Providing teachers with correct and thorough knowledge about the causes and effects of stuttering can have a positive influence on the way teachers interact with students who stutter. In their study of elementary school teachers, Crowe and Walton (1981) found that teachers with a greater knowledge of stuttering had more positive attitudes toward stuttering. Specifically, providing knowledge that reduces the perception that stuttering stems from a psychological cause has the potential to minimize instructor blame toward PWS (Boyle, 2016). However, Boyle (2016) found in his study of undergraduate students that providing biological explanations for 
stuttering alone was not enough to reduce the stigmatization of PWS. He explained that the stability facet of attribution theory must also be addressed. It is necessary, then, for teachers to be presented "with evidence that people who stutter can make great progress with appropriate, personalized therapy that addresses the multidimensionality of the disorder" (p. 14).

\section{Attitudes about PWS}

\section{Attitudes about PWS}

As Boyle (2014) found, perceptions of internal controllability regarding stuttering can lead to stereotyping people who stutter. PWS routinely suffer from social stigmatization, leading to inaccurate perceptions and overgeneralizations about their ability, intelligence, and personality. For example, Hughes et al. (2010a) found in their survey of 146 university students that the majority referenced negative characteristics when asked to imagine themselves as a person who stutters. Participants stated that they would feel depressed, isolated, and frustrated. They believed that making friends, finding romantic partners, and achieving a career would all be limited because of the stutter. Very few indicated that they would accept themselves as a PWS or that they would make an effort to learn how to overcome criticism and doubt. These attitudes are echoed by Van Borsel et al., (2011) who found that adolescents are less likely to find PWS attractive and are less likely to engage in a romantic relationship with them.

In a separate study, Hughes et al., (2010b) used an open-ended questionnaire to survey 149 fluent university students about how they would describe a PWS and why. They found that participants had both positive and negative perspectives about PWS. The positive reports included describing PWS as caring, patient, kind, accepting, intelligent, and normal. The positive characteristics emphasized that PWS do not have different qualities than anyone else. Alternatively, many participants imagined that PWS are probably more understanding and caring 
because of previous negative experiences with being labeled as "different". The negative reports stated that PWS are annoying, impatient, frustrated, angry, shy, and mentally impaired. In some of the negative reports, participants explained that they knew the PWS could not help the stutter, but they found it funny, annoying, or frustrating anyway. The authors explain that statements describing PWS as having low communication competence tempered many of the positive comments. They note, "PWS, who are perceived as warm individuals but incompetent communicators, are likely to invoke emotions of pity" (p. 295) in fluent listeners. These listeners may engage in attempts to actively help the PWS, such as filling in missing words or providing advice about how to stutter less. Pity may also lead fluent listeners to participate in passive, but harmful, behaviors such as avoiding interactions with PWS, not offering employment to PWS, or reducing speaking opportunities for PWS (Hughes et al., 2010b).

\section{Attitude and Familiarity with PWS}

Arnold et al. (2015) posit that, ideally, "teachers can counteract the potentially negative effects that inaccurate public beliefs about stuttering may have on their students who stutter" ( $p$. 29); however, the research about teacher attitudes has been inconclusive. Irani and Gabel (2008) found that teachers reported positive attitudes about both PWS and fluent students; however, teachers rated a hypothetical PWS as more intelligent, more sincere, and more physically normal than a hypothetical fluent peer. Other studies have found that teachers and non-teachers do not differ in their attitudes toward PWS, but that teachers who are female, older, have more education, and are familiar with a PWS tend to have more positive attitudes about PWS (Arnold et al., 2015). Further studies have found that individuals who are familiar with people with disabilities often have more positive attitudes about accommodating these students (e.g., Boyle, 2016; Brockelman, Chadsey, \& Loeb, 2006). Yeakle and Cooper (1986) found that 
approximately half of the participants in their study indicated that students who stutter are shy, quiet, and nonverbal, and half of the teachers indicated that they would find it difficult to know how to react to a PWS in the classroom. Zhang et al. (2010) explain that a teacher's willingness to provide accommodation for students with disabilities is influenced by his or her attitude about the ability of students to be as successful as the student's peers. The authors note that teachers "want to see that their time and effort are worthwhile" (Zhang et al., 2010, p. 284); therefore, it is important to make instructors aware of the potential that students with disabilities have for academic achievement.

\section{Attitude and Disability Training}

The influence that training can have on improving attitudes toward individuals with disabilities has varied. In their study on training general education instructors about special education students, Carroll, Forlin, and Jobling (2003) discussed that training can decrease feelings of discomfort and distress (which the authors describe as pity) toward students with disabilities. The authors found that teachers who completed a 10-week training course demonstrated less pity toward special education students and were able to focus more on the student rather than the disability. Similarly, in their study of 603 pre-service teachers who received training about people with disabilities, Sharma, Forlin, and Loreman (2008) found that participants became significantly more positive about individuals with disabilities after receiving training. However, Hastings, Hewes, Lock, and Witting (1996) found in their study of 100 student teachers who completed a special education course that the course did not affect the teachers' attitudes.

As basic communication course instructors often teach first-year university students (Hunt et al., 2009), their willingness and ability to accommodate a student with a disability 
(including students who stutter) can have a profound influence on that student's collegiate future. Teachers may be able to help students who stutter manage social challenges related to negative attitudes from peers (Franck, Jackson, Pimentel, \& Greenwood, 2003) and accurate beliefs and positive attitudes from teachers may function to improve peer relationships between PWS and fluent students (Arnold et al., 2015). However, it is also important that teachers perceive they are able to successfully accommodate a student who stutters, and that they have the knowledge to be able to do so. The next section will address teacher self-efficacy and training.

\section{Self-Efficacy and PWS}

Research has shown that instructors report wanting to assist students with disabilities, but are often unsure of how to do so. Marshall et al. (2002) found that when trainee teachers were asked about their ability to accommodate students who stutter, $81.2 \%$ said that they believed it would be a positive challenge, but only $10.7 \%$ stated that they would feel competent. Most of the participants explained feeling nervous, apprehensive, and anxious about having a student with a speaking disorder in the classroom, and the majority cited a lack of preparedness or institutional support. Daniels et al. (2011) found that professors listed similar obstacles. While all the participants in their study noted that a supportive classroom environment with as supportive instructor would be important for the success of a student with a communicative disability, several said that they were unsure of how to handle accommodations and noted a lack of knowledge and experience as main stumbling blocks.

\section{Defining Self-Efficacy}

Self-efficacy serves as a central component of Bandura's (1997) social cognitive theory; however, he isolated the concept for further study (Housley Gaffney \& Frisby, 2013). (Bandura (1997) describes self-efficacy as "beliefs in one's capabilities to organize and execute the course 
of action required to produce given attainments" (p. 3). This is the self-confidence an individual has in his or her ability to successfully exhibit or perform a behavior. Bandura identified four sources that contribute to an individual's level of self-efficacy: (a) mastery experiences, such as opportunities to personally execute a behavior successfully; (b) vicarious experiences, such as observing another person execute a behavior successfully; (c) social persuasion, such as support or encouragement from valued others about executing a behavior successfully; and (d) physiological states, which include senses or moods related to the target activity, such as stress, anxiety, or fatigue. Of the four sources, mastery experiences tend to have the greatest effect on self-efficacy development, because they are the most authentic indicator of an individual's abilities (Bandura, 1977). In general, individuals who are high in self-efficacy "consider most tasks to be manageable, feel confident, and perceive their behavior to be useful across contexts" (Housley Gaffney \& Frisby, 2013, p. 211) when compared with people who are low in selfefficacy. Bandura (1977) explain that self-efficacy theory has two central concepts that are related but distinctive: outcome expectancies and efficacy expectancies. Outcome expectancy is an individual's belief that a specific behavior will lead to a specific outcome. Efficacy expectancy is defined as an individual's conviction that he or she can successfully perform the behavior that is required to produce a specific outcome. Bandura (1977) notes that these expectancies are separate, as an individual may believe that a certain behavior will produce certain outcomes, but if the individual "entertain[s] serious doubts about whether they can perform the necessary activities such information does not influence their behavior" (p. 193). People who view a situation as exceeding their efficacy ability tend to avoid the situation and view it as threatening. However, the stronger an individual's perceived self-efficacy is, the more likely they are to engage in coping efforts, expend more effort, and persist in the face of 
adversity. Bandura (1977) explains, however, that expectation alone will not produce action if an individual lacks the capabilities to perform. Individuals must also be given "appropriate skills and adequate incentives" (p. 194) to determine a path of action.

In their research on motivation, Margolis and McCabe (2006) explain that enactive mastery experiences refer to an individual's recognition of the degree to which they can achieve a task. By actively engaging in an activity, individuals can see for themselves whether or not they are able to successfully perform a behavior. Successful experiences raise mastery expectations, while unsuccessful experiences can lower expectations, especially if individuals perceive that they are unable to successfully perform in the early stages of learning (Bandura, 1977). However, after repeated success, "the negative impact of occasional failures is likely to be reduced" (Bandura, 1977, p. 195). Margolis and McCabe (2006) suggest that individuals recognize more success when they begin with moderately challenging tasks and can experience achievement gradually. Vicarious experiences allow individuals to observe another person performing a behavior, and can provide learners with specific guidance about how to perform a task (Margolis \& McCabe, 2006). Vicarious experiences offer information about how others can model a behavior and can influence self-efficacy beliefs by "demonstrating and transferring competencies... and by providing a point of reference for social comparison" (Pfitzner-Eden, 2016b, p. 2). Vicarious experiences may allow individuals to see the success of another and develop beliefs about their own ability to perform similar tasks. Vicarious experiences tend to be most influential on self-efficacy development when learners have little experience in performing a task (Pfitzner-Eden, 2016b). Social persuasion is generally most effective when those offering suggestions about actions are seen as experts (Margolis \& McCabe, 2006; Pfitzner-Eden, 2016b). Social (or verbal) persuasion is beneficial because it is easily accessible (Bandura, 1977) and can 
allow advice-givers to offer task-specific feedback (Margolis \& McCabe, 2006). Bandura (1997) explains that social persuasion is more effective when people are also provided with aids for effective action. Individuals should not only be told "you can do it" but also "here is what you should do". Finally, physiological states, or emotional arousal, can influence self-efficacy beliefs. Typically, individuals are more likely to experience successful performances when they are not tense or agitated (Bandura, 1977; Pfitzner-Eden, 2016b). However, physiological arousal can also have an energizing function, such as in potentially stressful situations that can be controlled (Bandura, 1977). Self-efficacy is a valuable construct in training, and can provide teachers with the motivation to perform specific behaviors.

\section{Self-Efficacy and Disability Training}

Despite the rising number of students with disabilities in higher education (Abreu, Hillier, Frye, \& Goldstein, 2016; Eckes \& Ochoa, 2005), teachers are often provided with little to no training in how to interact with these students (DeSimone \& Parmar, 2006). This is a problem that must be examined, as instruction about accommodating students with disabilities can influence teacher self-efficacy and teacher attitudes toward inclusion, and because inclusive education is widely recommended to foster both academic and social outcomes for students with disabilities (Ruppar, Neeper, \& Dalsen, 2016). Teachers who receive consultation on how to accommodate students with disabilities experience lower levels of learned helplessness and higher levels of self-efficacy (Gotshall \& Stefanou, 2011). In a study concerning the self-efficacy and attitudes of Australian primary school teachers, Vaz et al. (2015) found that teachers who experienced lower self-efficacy had more negative attitudes about the prospect of inclusion classrooms with students with disabilities. Brady and Woolfson (2008) found that teachers who experienced higher self-efficacy were more likely to attribute learning disabilities to 
environmental factors than teachers with lower self-efficacy. The authors explain that, "teachers who feel more competent and have a greater belief in the power of their profession are more comfortable in accepting some responsibility for the children's difficulties" (p. 540).

Additionally, teachers with higher levels of self-efficacy are more likely to meet the needs of their students (Kosko \& Wilkins, 2009). Providing knowledge about specific legal requirements regarding students with disabilities may be beneficial for instructors as well, as several studies have shown that many faculty members and administrators at higher education institutions are unfamiliar with the requirements of Section 504 and the ADA (e.g., Katsiyannis, Zhang, Landmark, \& Reber, 2009; Vasek, 2005; Wilson, Getzel, \& Brown, 2000). This lack of knowledge is concerning, as Rao and Gartin (2003) found that there is a strong relationship between faculty members' willingness to accommodate a student with disabilities and their knowledge about laws regarding accommodation.

Training programs for teachers are most successful when they utilize mastery experiences because they provide "authentic evidence" (Pfitzner-Eden, 2016a, p. 241) about a teacher's ability to accomplish a goal. These mastery experiences are not always possible however, depending on time, availability and resources, so training programs may resort to the other three sources of self-efficacy. Kosko and Wilkins (2009) suggest that in addition to the type of training made available to teachers, the amount and length of training also plays a significant role. In their study on teachers' belief in their own ability to accommodate students with Individualized Education Programs (IEPs), the authors found that eight or more hours of professional development (such as training) was more than twice as effective as less than eight hours of professional development in improving teacher self-efficacy. They note that while any amount of time could increase teacher self-perceived ability, at least eight hours had the greatest impact. 
Other studies however, have found varied results. Taliaferro and Pilkington Harris (2014) conducted a study on the effects of a one-day workshop on physical education teacher's selfefficacy toward inclusion for students with autism and found that the workshop did not significantly affect the teachers' self-efficacy to include these students.

The instructional information offered in a training session is also an important factor in teachers' perceptions of the usefulness of training. In their study of middle school math teachers, DeSimone and Parmar (2006) found that most of their participants indicated that the preservice teacher training they received did not equip them to successfully interact with or accommodate students with learning disabilities in their classroom. Participants noted that most of the training focused on general descriptions of disabilities and special education laws. Most stated that they did not receive instructional strategies on how to best accommodate these students. Miller, Wienke, and Savage (2000) found that general education teachers who participated in workshops that focused on specific instructional, learning, or behavioral strategies regarding teaching students with disabilities indicated a significant increase in their perceived ability to teach these students. The influence of professional development may have noteworthy implications for teachers and trainers as Kosko and Wilkins (2009) determined that "professional development was found to be a better predictor of teacher's improved perceptions of their ability to adapt instruction for students with [Individualized Education Programs] than years of experience teaching students" (p. 8). Because of the influence that training can have on educators, it is important for universities to provide teachers with proactive education about accommodating students with disabilities and not wait to provide information until a problem arises (Zhang et al., 2010). 


\section{Current Study, Hypothesis, and Research Questions}

The current study explores an important gap in the communication research about the perceptions basic course instructors have about students who stutter and about a training session regarding students with disabilities. It is interesting to note that almost all of the literature concerning people who stutter has been conducted by scholars outside the field of communication studies. Researchers in the fields of biology, psychology, and communication sciences and disorders have studied PWS, yet this disability that has the potential to uniquely influence the field of public speaking has scarcely been addressed within communication. In fact, little research about accommodating students in general in the basic communication course classroom has been conducted. Since the attitudes that instructors have about students can influence student learning outcomes, it is important to assess how instructors perceive their students. Attribution theory states that individuals who exhibit behaviors that are seen as negative and controllable (or internal) are viewed more negatively than when the behavior is seen as uncontrollable (or external). This leads to the following hypothesis:

$\mathrm{H}_{1}$ : $\quad$ Basic communication course instructors who attribute the source of stuttering to psychological (internal) causes will have more negative attitudes toward people who stutter than those who attribute the source to biological (external) causes.

The attributions individuals make about PWS can have an influence on their attitudes and their self-efficacy toward PWS. Training also has the potential to improve instructor attitudes about people with disabilities (Carroll et al., 2003; Sharma et al., 2008) and their perceived selfefficacy (Gotshall \& Stefanou, 2011; Vaz et al., 2015). Therefore, the following research questions are proposed: 
$\mathrm{RQ}_{1 \mathrm{a}}:$ Is there a difference in attitude toward people who stutter between basic communication course instructors who receive training on how to supportively interact with PWS and instructors who do not?

$\mathrm{RQ}_{1 b}$ : Is there a difference in self-efficacy in dealing with people who stutter between basic communication course instructors who receive training on how to supportively interact with PWS and instructors who do not?

While training may be a valuable factor in influencing instructor attitudes, research shows that individuals who are familiar with PWS may have more positive attitudes about them (Arnold et al., 2015) and about accommodating them in the classroom (Boyle, 2016; Brockelman et al., 2006). Considering this information, the following research question is proposed:

$\mathrm{RQ}_{2}$ : Will basic communication course instructors who have had prior experience with PWS have more positive attitudes toward students who stutter?

Research has suggested that individuals who are more knowledgeable about PWS typically have more positive attitudes toward them (Boyle, 2016; Crowe \& Walton, 1981) and instructors who believe that they are capable and knowledgeable typically have higher perceived self-efficacy and are more likely to meet the needs of students with disabilities (Kosko \& Wilkins, 2009). As this study seeks to determine the effectiveness of a training session regarding instructor attitudes and perceived self-efficacy, the following research questions are proposed:

$\mathrm{RQ}_{3 \mathrm{a}}$ : Was the training effective in positively changing instructors' attitudes?

$\mathrm{RQ}_{3 \mathrm{~b}}$ : Was the training effective in positively changing instructors' perceived selfefficacy? 
Finally, this study seeks to determine the overall perceptions that instructors had about the training. To successfully engage in evaluation and assess learning, efficiency, and identify further opportunities for the training, the follow research question is proposed:

$\mathrm{RQ}_{4}$ : What perceptions do basic communication course instructors have of a training session concerning accommodating students with disabilities, specifically the communicative disability of stuttering?

\section{Conclusion}

This chapter examined the literature surrounding stuttering, including the causes and effects of stuttering, and the perceptions of PWS. Additionally, this chapter made the case for why a training session about accommodating students with disabilities (including stuttering) should be presented to instructors who teach the basic communication course. Bandura's (1977) theory of self-efficacy helped inform strategies trainers can use to motivate instructors and increase their self-efficacy about disability accommodation, including mastery experiences, vicarious experiences, social persuasion, and physiological states. This chapter explored the use of attribution theory in examining how individuals view PWS and how they may form attitudes about PWS based on the attributions they make regarding the root cause of stuttering. As more and more individuals with disabilities enter higher education, it is imperative to explore how to accommodate them. The follow chapter looks at the methods used in this study. 


\section{CHAPTER III}

\section{METHODS}

This chapter provides a comprehensive description of the methodology used in this study. A description of the training and development process, including the use of the ADDIE model, is discussed, followed by a description of the use of quantitative research and qualitative research. This chapter will also provide information about the study's sampling plan, a description of the participants, data collection procedures, confirmability measures, and limitations.

\section{Training and Development}

\section{Description of the ADDIE Model}

Gustafson and Branch (2002) define instructional design as "a system of procedures for developing educational and training programs in a consistent and reliable fashion" (p. 17). The authors explain that while there are a variety of instructional design processes, "the core elements include analysis, design, development, implementation, and evaluation (ADDIE) to ensure congruence among goals, strategies, and evaluation" (p. 18). Each phase of the model has a distinct purpose and specific function within the framework (Peterson, 2003). The ADDIE model is not a series of steps in a pre-defined line, but rather "a cyclical process that evolves over time" (Peterson, 2003, p. 228) The Analysis Phase may be the most vital (Hannum, 2001) as it involves an analysis of the environmental and organizational atmosphere of where the instructional program will take place. Here, the trainer can assess how the environment (such as the work place, the management, or the organizational culture) may influence and affect the training. In the Analysis Phase, it is important to conduct a needs assessment to determine if a problem exists, a performance analysis to identify causes and solutions of the problem, and finally a task analysis to determine what the trainee must be able to do (Hannum, 2001). In the 
Analysis Phase, it is important for the trainer to determine the needs of the trainees. Beebe, Mottet, and Roach (2012) note that it is important to make sure that a development session is a training process, not just an educational process. It is valuable to not only determine the knowledge that participants may need to know, but to also examine the skills or attitudes that trainees may lack; Goldstein and Ford (2002) explain that learning outcomes including knowledge, skills, or attitudes (KSAs) must be identified to measure improvement. They note that improvement is "measured by the extent to which the learning that results from training leads to meaningful changes in the work environment" (p. 22).

The Design Phase encourages the trainer to become an architect; the trainer creates the blueprints for what the program should entail. In this phase, the trainer utilizes the information gathered during the Analysis Phase to develop program goals, outcomes, and objectives (Hannum, 2001). The goal of the program is the focus or aim of the curriculum (Schreyer Institute for Teaching Excellence, 2017) or the overall change to the environment (Hannum, 2001). A goal will have several outcomes, which indicate specific KSAs that learners are expected to acquire ("Goals, Outcomes, and Objectives", 2017). Each outcome, then, may have several objectives, which focus on what trainees will be able to do at the end of the program (Beebe et al., 2012; Callahan, 2005). Beebe et al. (2012) comment that objectives should be observable, measureable, attainable, and specific. The trainer should have a concrete method of determining if the outcomes and objectives were met.

While the Design Phase describes what is to be accomplished, the Development Phase describes how to accomplish the goal (Hannum, 2001). In this phase, the trainer must determine what factors are likely to enhance effective instruction and promote learning (Hannum, 2001). Here, the trainer must consider potential instructional methods, techniques, and media. 
Instructional methods should be designed to allow trainees to select important points from within material, engage in building relationship between points, and develop conceptual links between the training and their own knowledge or experience (Robotham, 2003). It is important for the development phase to be created around the learning process, rather than the actual content to be learned, in order to help the trainer avoid "an inherent danger in encouraging individuals to adopt a particular learning style, in the belief that it constitutes a 'good' style" (Robotham, 2003, p. 475). To help learners process content, Beebe et al. (2012) suggest that trainers should build in moments for trainees to internalize what they are learning every eight minutes. This encourages what Robotham (2003) refers to as a "stimulus-stimulus approach" (p. 447), in which the participants are "actively involved in both learning and the mechanics of the learning process itself" (p. 477) In the Development Phase, it is necessary for the trainer to keep in mind both the characteristics of the trainees (Beebe et al., 2012; Goldstein \& Ford, 2002) and the needs of key stakeholders (Kirkpatrick \& Kirkpatrick, 2009). In this phase, it is vital for the trainer to develop beneficial partnerships with individuals and groups who are invested in the needs of the organization. Kirkpatrick and Kirkpatrick (2009) aptly state, "Business partnerships, not the delivery of the training programs, is the secret to positive outcomes" (p. 5).

In the Implementation Phase, the trainer takes an active role in delivering the product (Peterson, 2003) and executing the learning process (Mayfield, 2011). The creator of the training materials may turn them over to the customer or sponsor for use (Greer, 2014) or may implement the training themselves. In this phase, the training takes place in the setting for which it was designed (Allen, 2006). The Implementation Phase is important as it provides real-time feedback from the field (Allen, 2006), which can allow future changes and improvements (Mayfield, 2011). 
Finally, the Evaluation Phase is when "creators assess learning goal achievement, training efficiency, technical problems that hinder learning, and any new learning opportunities identified during the implementation phase" (Mayfield, 2011, p. 20). In this phase, the trainer can determine if the goal, outcomes, and objectives were appropriate and attainable (Hannum, 2001). Goldstein and Ford (2002) emphasize the need to assess both what the trainees learned during training, as well as how that learning has been transferred to enhance performance within the organization. The evaluation phase is necessary, as it may provide the trainer with information to justify and validate the training (Wang \& Wilcox, 2006), and make necessary improvements for the future. As the ADDIE process is cyclical, the trainer is constantly evaluating and making adjustments during each stage; however, the evaluation phase is the culmination of each of the other phases (Wang \& Wilcox, 2006).

\section{Role of the Trainer}

The role of the trainer in the training and development period requires constant introspection. It is necessary that the trainer be more attune to the needs of the organization than their own personal aspirations for the training. Goldstein and Ford (2002) note that sometimes "programs do not achieve their full potential because trainers are more interested in conducting the training program than in assessing the needs of their organizations" (p. 25). Trainers must assess if their own learning style is biasing the training to only accommodate that particular style (Robotham, 2003). Additionally, trainers must put aside their pride in the evaluation stage.

Because the evaluation period may bring up failures in the training (Goldstein \& Ford, 2002), the trainer must be humble enough to ask for evaluation and humble enough to hear it. 


\section{Description of the Current Training Development}

The training I created, titled Classroom Management with Special Populations, took place on August 18, 2016 before the start of the Fall semester at a mid-sized Midwestern university. The participants consisted of 22 incoming GTAs, many of whom had never taught before, who would teach the basic communication course. A more detailed description of the participants can be seen in the quantitative methodology section. The curriculum was designed to train instructors about how to accommodate students with disabilities. The training first examined stuttering as a communicative disability that would uniquely influence the basic course, and then expanded to address student accommodations as a whole. The training was incorporated into the larger teacher training session that all GTAs were required to take.

Each stage of the ADDIE process was utilized to create this training. I began by analyzing the needs of the university, the basic communication course program, and the incoming instructors. Much of the analysis phase was accomplished by conducting interviews. As a GTA myself, I had attended the teacher training session the year before and noted the lack of instruction about how to accommodate students with disabilities. In my interview with the director of the basic course, I learned that the teacher training session had never focused solely on students with disabilities, and that this was an area that needed attention. Because many of the instructors would not have had previous teaching experience, it was unlikely that the participants would have received instruction on accommodation elsewhere. I also interviewed coordinators from the university's disability services office. I learned that this office wanted more opportunities to participate with departments on campus and inform instructors about the legal requirements of accommodating students with disabilities. They explained that instructors often only interact with the disability services office when they need to, which creates reactive 
conversations instead of proactive ones. Finally, I conducted interviews with a Speech Language Pathologist (SLP) who described the role that professionals play in accommodating students who stutter within the university. In these interviews, I discovered that both the disability services office and the basic communication course program wanted GTAs to be knowledgeable about how to accommodate students, but a lack of communication, time, and resources between the departments had prevented this from happening.

The information I gathered in the Analysis Phase allowed me to create the goal, outcomes, and objectives for this training (a complete list of the goal, outcomes, and objectives for this training can be seen in Appendix A) during the Design Phase. By determining the KSAs that were important for GTAs to acquire, I could assess what GTAs should accomplish by the end of the training, as well as ways to determine if these measures were met. In the Development Phase, I evaluated the techniques and methods that would create a learner-centered atmosphere and allow for a stimulus-stimulus approach. I had to continually check my own learning style to ensure that I was not only appealing to individuals who learn the way I do. By incorporating media examples, group discussion, lecture, and a question-and-answer session, I was able to accommodate a variety of learning styles, while allowing participants to continually assess they information they were internalizing. In the Development Phase, I partnered with learning professionals and other organizational partners by inviting the SLP and a coordinator from the disability services office to co-create the training with me.

In the Implementation Phase, I conducted the actual training. The training took place on a Monday, which followed an intensive week of teacher training for the GTAs and was an hour and a half long. Refreshments were provided and participants were invited to sit anywhere they wanted to in the classroom to create a pleasant physical environment for learning (Beebe et al., 
2012). After welcoming the participants and providing an overview of the schedule, I began by showing a video clip of a young adult describing his stutter. This created a consistent experience for participants, so that even those who were not familiar with someone who stutters would still be able to actively participate. Participants then engaged in a group discussion about their attitudes and perceptions of people who stutter. I then introduced the SLP and conducted an interview with her in front of the class. The SLP and I had arranged the questions in advance to ensure that we covered the necessary material appropriately. She explained what stuttering is, the causes of stuttering, the effects of stuttering, the strategies for handling stuttering, advice for teachers when interacting with a PWS, and potential accommodations that may be useful in the basic course specifically.

The training session then shifted to a discussion about how to accommodate students with other disabilities. I interviewed the coordinator from the disability services office and conducted an interview with her in front of the class. Like the SLP, we had arranged the questions in advance. The coordinator described the legal requirements for accommodating students, the process that students with disabilities go through to receive accommodation, the role of professionals in accommodating students, potential accommodations for the basic course classroom, and advice for teachers. Participants then had the opportunity to ask questions of the experts, relate the information to their own lives and knowledge, and gather information to address potential concerns in their own classrooms. Incorporating subject matter experts, and not presenting all the content myself, was a strategic design choice (Beebe et al., 2012) since individuals are more likely to be persuaded by people they perceive as specialists (Margolis \& McCabe, 2006; Pfitzner-Eden, 2016b). I then conducted a group discussion to engage participants in how the training session related to information they had learned the week prior 
about teaching the basic course. Participants discussed key takeaways from the training, practical steps they could use in their classrooms, and behaviors that they wanted to exhibit (or not exhibit) when engaging with students with disabilities. During this time, students were provided with a handout from The Stuttering Foundation about how to best interact with PWS. At the conclusion of the training, I ended by showing a video of the same young adult from the beginning of the training describing what he had learned about communication and accommodation because of his stutter.

Although I could not provide mastery experiences as Bandura (1977) describes them by allow students the chance to teach a student with a disability during the training, they were able to hear vicarious experiences described by the SLP and the coordinator, they were provided with verbal persuasion about their own ability to accommodate students and given specific provisions to achieve this goal, and physiological states were addressed by creating a comfortable, interactive, and non-threatening environment.

Finally, the Evaluation Phase was assessed in two parts. Before the training, participants were asked to complete a pre-test survey concerning their knowledge and attitudes regarding PWS. They were then sent a posttest to measure the same variables three months later (see the quantitative methodology). Additionally, trainees were invited to participate in focus groups to assess their takeaways from the training, including an assessment of the goal, outcomes, and objectives and ideas for future improvement. Information concerning the focus groups can be seen in the qualitative methodology. It was important to conduct the evaluation several months after the training to allow for instructors to have time to reflect. Turner (2006) explains that training sessions that do not allow participants time to reflect is "like drinking out of a fire hydrant with little time allowed for swallowing" (p. 138). One benefit of the timing of this 
training was that participants began teaching their class days later, allowing them the chance to apply what they had learned quickly (Kirkpatrick \& Kirkpatrick, 2009).

\section{Quantitative Research Methodology}

\section{Participants}

Two groups participated in the quantitative portion of this study. Group 1 consisted of 22

first-year Graduate Teaching Assistant instructors who attended a training session concerning accommodating students with disabilities (including students who stutter), while Group 2 consisted of 28 second-year Graduate Teaching Assistant instructors and Non-Tenure Track (NTTs) instructors who did not attend the training. All participants are instructors for the basic communication course at the same mid-sized Midwestern university. Group 1 was $61.9 \%$ female and $38.1 \%$ male. In Group 1, two participants indicated that they either currently have a stutter or experienced a stutter in the past, six participants indicated they had a close relationship with someone who stutters, and five participants indicated that they had taught someone who stutters. Group 2 was $73.3 \%$ female and $23.3 \%$ male. In Group 2, one participant indicated that he/she currently has a stutter or experienced one in the past, three participants indicated they had a close relationship with someone who stutters, and twelve participants indicated that they had taught someone who stutters. Self-selection was used to recruit participants who participated in this study.

\section{Procedure for Participants}

\section{Group 1.}

While participation in the training session about accommodating students with disabilities was a mandatory segment of the overall teacher training for GTAs, instructors in Group 1 were informed that their participation in this study was optional. Prior to the training, an email to 
recruit participants to take the pre-test survey was sent to all 22 incoming basic course GTAs. Participants were eligible to participate in the survey if they were at least 18 years of age and had never attended a training course about stuttering previously. Twenty instructors chose to participate in the survey section of the study. After reading the recruitment email, participants were linked to an online version of the pre-test survey, which required completion before the training. To be able to match pre-test responses and post-test responses with the appropriate participant, the survey prompted participants to create a unique identification number consisting of the two digits of their birthday month, two digits of their birth day, and the last four digits of their social security number. In an informed consent description, participants were assured that their responses to survey questions would be kept confidential, and that they could choose to discontinue the survey at any time without penalty. Participants were also informed that the survey was expected to take between 10-15 minutes.

Three months later, participants in Group 1 were sent a posttest, which was an exact replica of the pretest. Fourteen participants completed the posttest; however, two responses did not include a matching identification number, so those entries were removed resulting in 12 posttest responses. This sample was $66.6 \%$ female and $33.3 \%$ male. In this group, two participants indicated a current or previous stutter, no participants indicated a close relationship with PWS, and four participants indicated that they taught someone who stuttered.

\section{Group 2.}

A recruitment email was sent to 35 second-year GTAs and NTTs. A volunteer sampling produced 28 responses. Participants in Group 2 only took the posttest survey. Participants who responded to the email were linked to an online version of the post-test survey. In the informed consent description, participants were notified that their responses would be kept confidential, 
and they could choose to discontinue the survey at any time. Additionally, participants for this section were informed that the survey was expected to take between 10-15 minutes.

\section{Instrument}

The pretest and posttest surveys were exactly the same and used a three-part instrument. The first section included a modified version of Yeakle and Cooper's (1986) Teachers' Perceptions of Stuttering Inventory (TPSI) and Crowe and Walton's (1981) Teacher Attitudes Toward Stuttering (TATS) Inventory to measure instructors' knowledge and perceptions about students who stutter. This survey used a 5-point Likert scale that ranged from 1 (strongly disagree) to 5 (strongly agree). The TPSI was created by Yeakle and Cooper (1986) to assess a variety of facets related to the teacher's relationship with a student who stutters, including the perceived personality of a stutterer, the influence a stutter can have on a student, and the role a teacher plays in interacting with a stutterer. Because basic course instructors are not speechlanguage clinicians, nor do they generally interact with a PWS's clinician, question number 9 on the TPSI survey, which related to the effectiveness of speech-language clinicians, was omitted from this study.

Similarly, the TATS was developed by Crowe and Walton (1981) to assess teacher attitudinal beliefs about students who stutter as well as teachers' general knowledge about stuttering. For example, the survey questions asked teachers to indicate their agreement as to whether stuttering is curable, if students tend to stutter to get attention, and if stuttering is a psychological issue. This study was originally tested on elementary school teachers, so questions were altered or omitted to reflect the experience of a college instructor. For instance, question 10, “Teachers need to exercise extra patience in disciplining children who stutter", was not included. Any duplicate or redundant questions between the TPSI and the TATS were adjusted. 
The second portion of the instrument asked teachers to consider the following prompt: "Imagine that tomorrow a new student will be enrolling in your basic communication course. This student has a noticeable stutter. Please indicate your level of agreement with the following statements." This portion of the survey was designed to encourage teachers to consider how they would personally feel about having a student with a stutter in their classroom, their teacher selfefficacy in their ability to accommodate a stutterer, and how they would perceive this hypothetical student. This portion also used a Likert scale that ranged from 1 (strongly disagree) to 5 (strongly agree). The statements in this portion of the survey were inspired by a study conducted by Abdalla and St. Louis (2012), who used an adapted version of the Public Opinion Survey of Human Attributes - Stuttering (POSHA-S) in their research. Instructors indicated their level of agreement about ten statements including, "I would feel anxious interacting with this student" and "I believe this student is shy or fearful." A full list of questions can be seen in Appendix B.

Finally, the third section of this instrument asked for demographic information about the participant. Participants were asked to state their sex, age, level of education, and total number of years teaching. They were also asked to answer "yes" or "no" to the following questions: "Do you currently have a stutter, or have you experienced a stutter in the past?", "Do you have a close relationship with someone who stutters?", and "Do you currently or have you previously taught a student who stutters?"

\section{Procedure for Scales}

The 38 Likert-type scale questions were assessed to determine which measured selfefficacy and which measured attitude. To create variable groups, Likert-type questions were coded by topic to create specific scales for the variables. This process was first conducted to 
determine a scale for self-efficacy. Originally 23 items were identified as measuring self-efficacy in dealing with PWS. After running scale reliability, items were removed to improve Cronbach's Alpha. The final scale resulted in seven items that produced a very good Cronbach's $\alpha$ of .803 (DeVellis, 2003). The same process was conducted to determine a scale for attitude toward PWS. Originally 21 items were identified as measuring attitude. After running scale reliability, items were removed to improve Cronbach's Alpha. The final scale resulted in 14 items that produced a respectable Cronbach's $\alpha$ of .749 (DeVellis, 2003).

\section{Qualitative Research Methodology}

\section{Participants}

The qualitative portion of this study consisted of 13 participants from Group 1. An email to recruit participants was sent to all instructors who attended the training inviting them to take part in a focus group. Instructors were provided a list of potential dates and times, but informed that alternate options could be available as well. Of the 22 instructors who took part in the training session, 14 chose to participate in the study, yielding three focus groups. One participant, however, had attended the larger teacher-training session, but was unable to attend the section on students with disabilities and was unable to participate. The resulting 13 participants consisted of nine women and four men. While all participants were first-time university instructors, several had varying experiences teaching in other contexts. The first group consisted of five participants, the second group consisted of three participants, and the third group consisted of five participants.

\section{Data Collection}

Each focus group lasted approximately 45 minutes. In each, I used a semi-structured interview protocol (Morgan, 1997), which allowed participants to expand on the questions and 
organically introduce themes. Because I served as the organizer of the original training session on students with disabilities and was the conductor of the focus groups, I incorporated questions for participants to identify and explain any weaknesses or areas for improvement within the training session to help curb researcher expectancy bias and encourage participants to share freely. I asked participants open-ended questions about their experience during the training session (e.g., if they saw a benefit in hearing from a Speech Language Pathologist, how they felt about the amount of time spent on each portion of the training) and their experience as a teacher after the training session (e.g., what experiences they have had in the classroom that may warrant further training). I acted as the moderator to promote a positive group experience, facilitate conversation from each member, and keep the group on task (Krueger, 1988; Lindlof \& Taylor, 2011).

The focus groups provided a helpful method for gathering data for this study because of the linkages between each participant's comments. As opposed to one-one-one interviews, participants could build on one another's experiences in creating their own thoughts, an effect that Lindlof and Taylor (2011) refer to as "chaining" or "cascading" (p. 183). Before conducting each group, I briefly reviewed what happened during the training session and asked participants to mentally step out of the interview room and think back to the original training environment (Krueger, 1988). By examining their personal experiences during the training, and their current experiences as a teacher, both inside and outside the classroom, participants engaged in a group discussion that created a process of "sharing and comparing" (Morgan, 1998, p. 12).

\section{Procedure}

All focus groups took place in a secure, private room on the university's campus.

Participants were asked to read and sign an informed consent form, and were debriefed about the 
confidential nature of the study. They were informed that they would receive pseudonyms in any written work, and were asked to keep the identities of their fellow participants confidential as well. Participants were also informed that each focus group discussion would be audiotaped, videotaped, and transcribed verbatim. Finally, participants were given contact information for the university's disability and student accommodations office to assist them with any pressing needs.

\section{Data Analysis}

All interviews were transcribed verbatim, yielding 33 pages of single-spaced content. A sampling of questions can be seen in Appendix C. The first two transcriptions were then read to find emerging categories. Data were analyzed using Glaser and Strauss' (1999) constant comparative method where the responses from participants were first gathered into units of speech that encompassed important content characteristics. These units were then bracketed and grouped together. I then inductively developed several categories for units with similar characteristics (Corbin \& Strauss, 2015). Once categories were established, the third transcription was unitized and coded to discover any remaining categories. Finally, categories were analyzed for similarities and overarching connecting themes. It is important to note that I analyzed the qualitative data before analyzing the quantitative data to inductively develop categories in order to minimize potential bias from the results of the quantitative data. 


\section{CHAPTER IV}

\section{RESULTS}

The previous chapter explained the process of developing and conducting the training session on accommodating students with disabilities, as well as the procedure for collecting and analyzing quantitative and qualitative data. This chapter presents the results of the study. First the quantitative results will be presented, followed by the qualitative results. The statistical analyses performed were independent samples $t$-tests and paired-samples $t$-tests. Through these analyses, this chapter addresses the hypothesis and research questions presented in this thesis. The results presented here give insight into questions of knowledge, self-efficacy, and attitudes regarding PWS, as well as the perception that instructors have about the training session.

\section{Quantitative Results}

\section{Attribution Theory and Attitude (H)}

According to attribution theory, individuals who view the root cause of a negative behavior as internal, or controllable, have more negative attitudes toward the person committing the behavior than individuals who see the root cause as external, or uncontrollable. An independent samples $t$-test was conducted to determine if there was any difference in attitude toward PWS between instructors who view stuttering as having an internal, psychological cause and instructors who view stuttering as having an external, biological cause. This test was conducted using responses from individuals who viewed stuttering as internal $(\mathrm{n}=11)$ and instructors who viewed stuttering as external $(n=9)$. The Levene's test for equality of variance was not significant $(F=.801, p=.383)$, so equality of variance was assumed. There was no statistically significant difference between instructors who viewed the root of stuttering as 
psychological $(M=55.91, S D=5.32)$ and those who viewed the root of stuttering as biological $(M=60.67, S D=8.23), t(18)=-1.56, p=.14,95 \%$ CI $[-11.15,1.63]$.

\section{Attitude Toward PWS Between Trained and Non-Trained Groups $\left(R_{Q_{1 a}}\right)$}

An independent samples $t$-test was conducted to determine if there was any difference in attitude toward PWS between instructors who received training on how to supportively interact with PWS and instructors who did not. This test was conducted using responses from individuals who had received training $(n=12)$ and instructors who had not $(n=28)$. The Levene's test for equality of variance was significant $(F=6.36, p=.016)$, so equality of variance was not assumed. There was no statistically significant difference between those who received training $(M=59.67, S D=4.14)$ and those who $\operatorname{did} \operatorname{not}(M=57.14, S D=7.16), t(34.31)=1.40, p=.17$, $95 \%$ CI $[-1.15,6.19]$.

\section{Self-Efficacy Between Trained and Non-Trained Groups $\left(R_{Q_{1 b}}\right)$}

An independent samples $t$-test was conducted to determine if there was any difference in self-efficacy toward PWS between instructors who received training on how to supportively interact with PWS and instructors who did not. This test was conducted using responses from individuals who had received training $(n=12)$ and instructors who had not $(n=27)$. The Levene's test for equality of variance was not significant $(F=.061, p=.806)$, so equality of variance was assumed. Trained participants' $(M=26.58, S D=4.87)$ scores were statistically significantly different from the scores of non-trained participants $(M=21.93, S D=5.11)$.

\section{Attitudes and Prior Experience $\left(\mathrm{RQ}_{2}\right)$}

An independent samples $t$-test was conducted to determine if there was any difference in attitude toward PWS between instructors who had previously taught PWS and those who had not. This test was conducted using responses from individuals who had taught a PWS $(n=18)$ 
and those who had not $(\mathrm{n}=33)$. The Levene's test for equality of variance was significant $(F=$ $12.34, p=.001)$, so equality of variance was not assumed. Attitude scores for participants who had taught PWS $(M=60.72, S D=3.94)$ were statistically significantly different from participants who had not taught PWS $(M=56.12, S D=7.01)$.

An independent samples $t$-test was also conducted to determine if there was any difference in attitude toward PWS between instructors who had a close relationship with a person who stutters and those who did not. This test was conducted using responses from individuals who had a close relationship with PWS $(n=6)$ and those who did not $(n=45)$. The Levene's test for equality of variance was not significant $(F=2.88, S D=.09)$, so equality of variance was assumed. There was no statistically significant difference between those who had a close relationship with someone who stutters $(M=54.17, S D=9.13)$ and those who did not $(M=$ 58.22, $S D=5.99), t(49)=-1.46, p=.15,95 \%$ CI $[-9.63,1.52]$.

\section{Training Effect in Attitudes $\left(R Q_{3 a}\right)$}

A paired-samples $t$-test was conducted to compare the attitudes toward PWS of instructors before and after training $(\mathrm{n}=11)$. There was not a significant difference in the scores for attitude before training $(M=57.18, S D=6.72)$ and after training $(M=60.18, S D=3.92)$, $t(10)=-1.45, p=.177,95 \% \mathrm{CI}[-7.61,1.61]$

\section{Training Effect in Self-Efficacy $\left(R_{Q_{3 b}}\right)$}

A paired-samples $t$-test was conducted to compare the self-efficacy toward PWS of instructors before and after training $(n=12)$. There was a significant difference in the selfefficacy scores before training $(M=22.83, S D=3.54)$ compared to the self-efficacy scores after training $(M=26.58, S D=4.87), t(11)=-2.90, p=.015,95 \%$ CI $[-6.61,-.89]$. 


\section{Qualitative Results}

This study used qualitative data to assess $\mathrm{RQ}_{4}$. Results revealed that participants perceived the training session through three unique lenses: self-perception, student-perception, and logistical-perception. Each focus group centered around these topics, and while each participant had their own story to bring to the table, each viewed the training through these lenses and were affected by them, either during the training or in their classroom later. The following explains the themes and categories with a thick description (Lindlof \& Taylor, 2011) to define and support the findings. In the lenses of self-perception and student-perception, participants revealed the paradoxical nature of simultaneously feeling an increased ability to instruct students with disabilities and an increased apprehension about the possibility of teaching students with disabilities.

\section{Self-Perception}

\section{Increased Self-Efficacy.}

The first major theme that developed for the lens of self-perception was increased selfefficacy. Across the focus groups, there was a high level of consistency about the personal ability participants felt because of the training. Prior to the training, hardly any of the participants had received training on students with disabilities, and only two described interactions with people who stutter. An increase in knowledge provided a variety of experiences for the participants. Many participants stated that they felt an increased sense of ability because of new knowledge they received. These participants emphasized their capacity to communicate with the university's disability office, follow disability laws, and dialogue with students who have disabilities, including providing resources for students who are not yet registered with the office. Drew, an 
instructor with no prior teaching experience, described her interaction with a student in her class who needed accommodation:

If we hadn't have had that training I wouldn't have known that I'd need to ask for the [student's disability card]...I felt very, like, I understood what was going on and I could be like, ok, just let me know whenever that gets done and make sure it gets sent to me and we can do your accommodation. And I knew not to, like, ask about it because I think that's a natural thing if you don't know not to is to be like, oh, what are you getting accommodated? But I knew not to ask about that and just to say, oh, well, whenever that comes to me then I can work things about with you at that time. So, I felt very prepared to deal with that. (1:92-100 [notations reflect focus group number and transcript line numbers])

Drew's experience reflects her level of preparation. Even participants who had previous teaching experience commented on the increase in self-efficacy that they received because of the training. For example, Jordyn, an instructor with teaching experience, explained that in her case, she already felt confident about her ability to interact with students, but was unsure about the process of accommodating students at the university level.

I was just glad I was told what to do when issues come up because in my past experience, it's just been, ok, figure it out... so seeing the process at the college level really helped me. The week was very different for me in general anyways, so I was happy to kind of- I felt like I was getting something that was useful with that session. (2:64-70) Other participants, however, described self-efficacy in terms of what they did not know beforehand. While Drew and Jordyn both described their new capability to have a discussion with a staff member or a student about disabilities, several participants emphasized the lack of 
understanding they had about the topic. For instance, Matt, an instructor with no prior teaching experience, explained that prior to the training, his lack of knowledge was hindering his selfefficacy and that during the two weeks of teacher training, he wanted to know more about accommodations.

I had heard [the student disability office] name mentioned, but I didn't know exactly what they did or even, um, that students could just go there to sort of find out "Are there accommodations that can be made for me if I have an issue?" And so that was something I was wondering about sort of throughout the training, like what do we do if we have a student who has a special accommodation that needs to be made? (3:89-43)

Similarly, Chris, an instructor with no prior teaching experience, joked about the group discussion section of the training where instructors discussed their beliefs about people who stutter.

So, I think it came down to the discussion being kind of the moment where it was like, this training session is important because of how poorly the discussion is going without any sort of basis to guide it with. Just because- the discussion itself was great- because it was able to kind of show everyone, like, we don't really know what stuttering is. (3:32$35)$.

Chris' insecurity about understanding the roots of an issue that could affect a student's communication are evident in his statement. Several participants, like Whitney, an instructor with no prior teaching experience, explained that this knowledge was not even on her radar. She explained, “Just-it just felt nice feeling prepared for it, and it wasn't even something that, like, I had even thought of." (3:34-35). Jasmin echoed Whitney's comment when she stated, "It just felt 
nice feeling prepared for it, and it wasn't even something that I had even thought of. And so when the training came up I was like, oh, I didn’t even think of this.” (3:284-286).

Finally, several participants described feeling a sense of self-efficacy because of a decrease in anxiety. For first-time instructors, there is often already a heightened sense of anxiety about teaching a class and navigating a curriculum. Similarly, very few new instructors are prepared to handle the challenge of accommodating a student with a disability. Participants in each focus group described how their anxiety about teaching was lowered. Jessie, an instructor with no prior teaching experience, explained:

At first, like, I hadn't even thought that I might have a student with a speech impediment, and then I was like, holy guacamole, this might be a thing, and it made me very nervous, but then everything that [the SLP] told us, I was like, oh, it's going to be ok. (1:31-34) This category speaks to the necessity of training and the type of information teachers need to be provided with. Instructors need to not only know information about disabilities, but also, about how those disabilities are managed and accommodated. For Mike, an instructor with no teaching experience, the two weeks of teacher training was exhausting; however, just having the knowledge of where to go in the future if a need arose was enough to calm his nervousness. It was like, I don't have to stress, or like worry, if I get a student who has one of these challenges I can go talk to the right people then and I know how to get the help for them, which was important for me going into teaching. I hadn't taught before, and that was my best thing out of it was- I may not know everything on how to help them right now, but I know who to go to talk to; we'll get that taken care of if we need to. (2:39-44) 


\section{Feelings of Inadequacy.}

However, many instructors also echoed the opposing theme. While almost all the participants expressed encouragement about their ability to interact with the office of disabilities and more confidence about interacting with students who stutter, a prominent theme was also lingering inadequacy. Some participants expressed that while they were informed in general about the office of disabilities, they did not feel confident or secure in their knowledge of what the office could provide their student. Kathryn, a first-time teacher, explained that she realized this inadequacy when she took a student with a disability to the office.

I walked up there with one of my students, and I still think he felt kind of lost there, too. And I couldn't really give him instructions. I just brought him there and was like, ok, they will take care of you and he was like, oh, so you're leaving? Because I didn't know what to do, right? $(3: 102-105)$

Kathryn's uncertainty was expressed by participants in every group. Whitney described wanting further information about accommodating students "because I did feel kind of helpless." (3:84-85) While many instructors described helping students seek accommodation, some instructors described that the challenge with the specific disability-specifically anxiety and depression-left them unnerved. Aurora, an instructor with no prior teaching experience, explained that helping students navigate mental disabilities was incredibly challenging.

I've had a situation where a student came up to me and said, 'I'm suicidal' and in that exact moment I panicked because I was like, I don't- besides telling you, like, you can go to the student counseling services, and she was like, "I am getting- like I am going already. I still just feel so alone. I know you said we could talk to you about it", so I was like, ok. So we talked for like an hour and a half about stuff, and at the end, I don't know 
if I helped her or not, because I don't know what I could say to her to help her. (3:219225).

In addition to feeling personally inadequate, participants expressed wanting more knowledge and resources about a wider variety of topics. Once this theme surfaced in each group, I asked participants what specific disabilities training they would want to receive. Responses ranged from anxiety and depression to ADHD/ADD to seizure disorders. Many participants expressed wanting further information about ways to help all students who need extra assistance, and not just students with disabilities. One example that came up in the focus groups was English as a Second Language (ESL) students. Jay, an instructor with prior teaching experience, explained that having ESL students in his class without receiving training is "like being thrown into a classroom and not knowing what to expect, and being expected to just survive.” (1:288-289)

\section{Student-Perception}

\section{Increased Empathy and Understanding.}

When reflecting on the training session, all participants discussed their current students, and increased empathy and understanding was a main theme. Several instructors described a change in attitude about students with disabilities and described accepting their students as they are. This meant both not being impatient with their students and not "babying" students who are capable of performing assignments. Kathryn described a student with a stutter in her class, and explained "I had a feeling that it was easier for me just to, you know, just to listen to him, and not say, 'come on, just talk' and be calmer." (3:24-25). Drew explained that she would have felt tempted to coddle a student with a stutter and not require him/her to give a speech. She said, "You automatically just want to be like, 'It's ok!' So, I think the training kind of helped reign 
that impulse in a little bit, and helped me, um, to really view it more as an instructor instead of just as a sympathetic human.” (1:318-323) Amber, an instructor with no prior teaching experience, stated that learning about students who stutter gave her a new understanding about students with disabilities as a whole.

I think it's made me a little bit more empathetic of a person in general. Like, I try to be a very understanding person, but before in my mind it would be like "Oh my goodness, ok..." and people who stutter, or speak really fast, or you know some of those like- even with little quirks in front of the classroom, but it's made me stop and think that "Ok, they can't really help this." And just, kind of made me see the world, generally, like my class for who they are, and take into perspective what they're going through... this is something that they can't help and how would I feel if I were in their shoes type of a thing. (1:331-341).

Another category participants described was being more understanding toward themselves in the classroom. Several expressed that having students with disabilities and behavioral issues made them question if they were a bad teacher. Kayli, an instructor with no prior teaching experience, explained that her experience with a student with ADD was originally frustrating: "I think especially at the beginning I would look out and be like, why is she talking all the time? It must be me. I think she's so rude. And I really am upset about this." (1:272-274). However, Kayli later identified that her teaching was not to blame: "So, I think it helped me with an attitude change and just seeing, like, hey, it's really nothing that I'm doing, they're just going to be the way that they are sometimes, and addressing it or helping other people see that I think just helps." (1:277-279). 


\section{Future Concern.}

While many participants expressed empathy and understanding, several also expressed concern about interacting with students with disabilities. Jessie, for example, described a disruptive student in her class with ADHD who has inappropriate and random outbursts. She stated, "as much as I can try to reign it back and like, alright, and just try to ignore him and like not feed into whatever attention-seeking behaviors he's doing, like I don't actually know how to combat that." (1:505-507) Ashley, an instructor with no prior teaching experience, stated that, overall, the training made her feel anxious. Unlike Jessie, she was concerned about the potential of future students with communicative disabilities.

I actually hadn't really thought about what would happen if I got a student who stuttered, wasn't even on my radar. So, I guess I would say that I had low-level anxiety about that, and then we talked about it, and then I got higher-level anxiety about it [laughs]. Oh dear, I might have to deal with this. (1:304-307)

\section{Logistical-Perception}

\section{Desiring Specific Resources.}

In addition to wanting more information about disabilities and services to help students, participants described desiring specific tools as a prominent theme. The training was an inperson, hour and a half long session, and a single page pamphlet was handed out at the end. Instructors expressed wanting further tangible and intangible (e.g., online) resources. Drew, Jay, and Amber discussed a wish for a list of resources to be emailed every semester, while Chris and Kathryn emphasized wanting a list in a static place on the school's intra-net site. Amber stated, "Even at minimum, just like a list or something that we- or like, electronic- like here's the 
different resources, here's like their contact info, and here's where on campus you can find them" $(1: 173-175)$.

For other instructors, having specific resources involved human interaction. Participants described wanting to interact with the office of disabilities with more consistency. Mike said that this was valuable because "when we do need to talk, we're going to talk to people we know. Not just people we saw one time at a particular training. When we see people on a regular basis, we're much more inclined to go talk to them, and bring our issues, and get help." (2:455-458) Similarly, participants described wanting to hear more about the perspective of students who have a disability. Chris suggested, "If you could find a student with a stutter who was, you know, willing to speak out- they obviously can't speak for stutterers in general, but maybe the student perspective would have been nice." (3:71-73)

\section{Desiring Extended Time.}

Each focus group discussed that they wished the training session had been longer. They discussed wanting to continue the conversation about how to accommodate both students who stutter, and students with disabilities as a whole. Jay specifically described wanting more time focusing on specific disabilities, like stuttering, because much of this information is new to the instructors. He said, “Just because that's the first time I'm sure most of us have encountered that, and it's really cool. Like- oo yeah! Tell me more. If there's more, that would be great." (1:439441)

Instructors also described wanting extended training throughout the semester in addition to training before the school year starts. As a part of on-going teacher education, the instructors attend weekly meetings, and several suggested utilizing this time for disability training session. Drew explains that having several mini-lessons throughout the semester would be beneficial for 
both teachers and students. She says, “That helps spread it out a little bit, and so we'd be better prepared to help our students throughout the semester rather than just having it all at once, which we might not even remember in the first place once we actually get to teaching." (1:490-492)

\section{Valuing Expert Insight.}

Overall, participants were pleased to have expert insight from the SLP and representative from the office of disabilities. They valued both their first-hand experiences and stories from working with students with disabilities, as well as the way that the experts explained content. Chris explains:

I think the professionals definitely came in handy because it's, like, their job is to figure out the best manners in which to approach these situations, so hearing from them was definitely nice, because it's like, well, if this is how a professional is dealing one-on-one with a student, I don't need to have necessarily that educational background, but if this is how they're doing it, then that's how I need to be doing it. (3:337-342).

Kayli echoed Chris' sentiment by describing her interest in the expert's personal stories.

She said, "I thought it was really helpful because they had a lot of those first-hand experiences to say, I remember working with this specific individual, and here's the specific problems that they had, and here's how we specifically overcame those problems." (2:331-334)

Mike expressed his appreciation for the comfort of being able to ask experts difficult questions in a safe space. He stated:

That was a comfortable environment. A good, safe environment to ask any questions about it, where you're not going to ask someone with a disability about it because you don't want to- you just don't want to do it. That's not the right place. So, it was great to 
have that opportunity there where it was a safe place to ask specific questions about any disabilities, so I really liked that. (2:364-368).

\section{Conclusion}

This chapter presented results from the quantitative and qualitative portions of this study. The findings here suggest several things. First, the results indicate that instructors who attended the training not only had more perceived self-efficacy than instructors who did not take the training, but they had higher self-efficacy after the training than before. The qualitative data helped elaborate on this finding, as participants revealed that they felt more self-efficacy regarding PWS and in regard to students with disabilities in general, but still felt like they were lacking information about other specific disabilities and specific details regarding the university's disability office. Second, results revealed that although a statistically significant difference was not found in regard to instructor attitudes, the qualitative data revealed that instructors who participated in the focus groups described their increased empathy for students with disabilities. However, further research should be conducted on instructor attitudes to determine if individuals who receive training have more positive attitudes about PWS compared to instructors who did not receive training. The findings also revealed that instructors who had taught PWS had more positive attitudes toward PWS. Finally, the qualitative results revealed that, overall, instructors perceived the training positively and desire more training in the future. The next chapter discusses these results in depth and explains their implications to educators and trainers. 


\section{CHAPTER V}

\section{DISCUSSION}

Students with disabilities are a unique population that universities and instructors must be prepared to accommodate. As more students with disabilities enter higher education, the need to train instructors in how to accommodate them will become more pressing. In this thesis, I examined stuttering, the role of disability legislation, the value of the basic course as a framework for study, the lens of attribution theory, and the influence of attitudes, self-efficacy, and training, especially as they relate to college instructors. The previous chapter examined the construction of the training curriculum using the ADDIE model, and presented the quantitative and qualitative results that were obtained in this study. This chapter will provide a summary of the quantitative and qualitative findings, discuss the strengths and limitations of the study, and describe the implications this study has for stakeholders and future research.

The quantitative and qualitative findings from this thesis have the potential to inform future research and provide guidance for conducting further studies about accommodation training. Holistically, the qualitative data provided a fertile ground for research and rich descriptions of participants' experiences, while the quantitative data further informed these findings. It is important to note that before this study, the university had never provided accommodation training for basic course instructors. The goal of this study was to develop a deeper understanding of how accommodation training can influence instructor attitudes and selfefficacy. Because of the exploratory nature of this study, it was interesting to discover which parts of the training were particularly salient to participants. I knew that the sample size would be small due to the nature of the GTA program, which made the findings concerning selfefficacy even more exciting. The results that were found with the small sample size also provide 
grounds for testing this accommodation training with a larger sample of basic communication course instructors.

\section{Summary of Findings}

\section{Quantitative Analysis}

This study focused on the attributions, attitudes, and self-efficacy of basic communication course instructors in regard to PWS. The study utilized Likert-type scales to assess attitude and self-efficacy, and used attribution theory as a lens to examine instructor attributions. Both the quantitative and qualitative methods informed the Evaluation Phase of the ADDIE model. This was beneficial as the qualitative data was able to provide a deeper layer to the quantitative findings, which was especially helpful when the findings seemed to contradict. The hypothesis predicted that instructors who attribute the source of stuttering to psychological causes would have more negative attitudes toward PWS than those who attribute the source to biological causes. This hypothesis, however, was unsupported. Results revealed that no significant difference was found between participants in regard to attitude. In the qualitative evaluation, however, participants did discuss an increased understanding of the external nature of disabilities. For example, Amber indicated that while she may have previously experienced frustration in regard to students with disabilities, the training made her realize that "they can't really help this" (1:335). Amber's realization highlights the biological element of a disability and emphasizes her attitude shift.

Research question one explored if there was a difference in attitude and self-efficacy between instructors who received the training and those who did not. Results for $\mathrm{RQ}_{1 \mathrm{a}}$ revealed that no significant difference was found between participants in regard to attitude. However, it is important to note that due to the nature of the GTA population, the sample size was 
underpowered and the effects would have needed to be large to detect a difference. The evaluation from the qualitative data helped inform this finding, as instructors who participated in the training revealed increased empathy and understanding for students with disabilities. Results regarding self-efficacy, however, revealed a statistically significant difference in regards to $R Q_{1 b}$. Participants in the group that received training showed higher self-efficacy than the group that did not receive training. These findings are similar to previous research (e.g., Gotshall \& Stefanou, 2011) that demonstrate the positive relationship between self-efficacy and training. It is possible that an increased knowledge in the legal requirements for accommodation influenced participants' perceptions of their self-efficacy (Rao \& Gartin, 2003); however, in the qualitative results, participants revealed that knowledge about how to manage instructional strategies and university procedures had a large influence on their self-efficacy. It is interesting to note that even though the qualitative results revealed that participants also described feelings of inadequacy regarding their ability to accommodate students with disabilities, the results for $\mathrm{RQ}_{1 \mathrm{~b}}$ reveal that specifically in regard to self-efficacy concerning PWS, instructors reported increased self-efficacy. This finding may have implications about the specificity of information that is provided during training sessions.

Results for research question two revealed that instructors (both those who received training and those who did not) who had taught PWS had more positive attitudes toward students who stutter. This finding is valuable as it lends to the growing body of literature concerning attitudes and familiarity with individuals with disabilities. Instructors who had taught PWS previously may be more willing to help PWS (Boyle, 2016), experience less anger or dislike toward PWS (Boyle, 2016), and feel less helplessness regarding accommodating PWS (Gotshall \& Stefanou, 2011). It is also possible that instructors who have taught PWS previously have seen 
the students who stutter are just as capable as their fluent peers (Zhang et al., 2010). However, $\mathrm{RQ}_{2}$ also examined if instructors who have a close relationship with PWS have more positive attitudes toward PWS than instructors who do not have a close relationship with PWS. Results revealed no statistically significant difference. It is important to note that the sample size was underpowered, and results may be different with a larger sample size. As the Evaluation Phase of the ADDIE model allows for trainers to find potential future opportunities, it may also be beneficial in future studies to incorporate specific questions during focus groups about relationships with PWS.

Research question three explored if the training was effective in positively changing instructors' attitudes and perceived self-efficacy toward PWS. The results for $\mathrm{RQ}_{3 \mathrm{a}}$ revealed no statistically significant difference; instructors did not report significant attitude change after the training. However, the sample size was underpowered. One potential direction for future research is to test this research question again with a larger sample size. Interestingly, the evaluation from the focus groups revealed that participants did experience attitude change toward PWS. The findings were similar to those of Carroll et al. (2003), as participants described experiences of focusing on the student as an individual rather than on the disability as an allconsuming characteristic. The results for $\mathrm{RQ}_{3}$ revealed a significant difference in perceived selfefficacy toward PWS between pretest and posttest scores for instructors who received the training. This finding is strengthened by the qualitative data, which found increased self-efficacy to be the first major theme in participant focus groups.

\section{Qualitative Analysis}

Research question four sought to determine the perceptions that participants had of the training session. This study was prompted by my own questions about my personal capabilities 
as a teacher to accommodate students with disabilities in my classroom and after researching the topic for my own edification I learned that many teachers do not feel equipped, prepared, or knowledgeable about accommodating these students successfully. After analyzing the focus groups, I found that instructors perceived a training session on students with disabilities by examining themselves, their students, and the logistics of the training itself.

The first theme that developed was that of increased self-efficacy. Across the focus groups, participants commented on a sense of empowerment they felt because of the training, Instructors explained they could use content from the training in their own classrooms and while interacting with students. These real-life "mastery experiences" (Bandura, 1997) made them feel like they were successfully prepared in both interacting with the student and interacting with the office of disabilities. Even participants who had not needed to accommodate any of their students described that having the knowledge of what to do in the future provided them with a sense of personal-ability. Several participants explained that reflecting on how little they knew before the training made them feel a greater sense of self-efficacy. In this category, several instructors especially highlighted that they had never considered that they might have a student with a disability in their classroom. One participant commented, "We always just assume that we'll have the perfect case scenario class." (1:415). Further, participants identified increased selfefficacy as decreased anxiety. Some explained that the disability training helped calm their fears about accommodating students, while others expressed that an increased knowledge about university procedures made them feel more confident. Teacher's self-efficacy is considered a key predictor of behavior and action (Zee, Koomen, Jellesma, Geerlings, \& de Jong, 2016), and participants seemed to echo that finding. This sense of increased self-efficacy may help teachers create more positive classroom climates for their students, as teachers may be able to more 
effectively meet the needs of students with disabilities (Kosko \& Wilkins, 2009) and develop a classroom atmosphere that is welcoming to students with disabilities (Arnold et al., 2015).

Interestingly, several participants also expressed feelings of inadequacy and a lack of self-efficacy. This was originally surprising as Kosko and Wilkins (2009) found that amongst early childhood, K-5, and course-specific teachers, "professional development was found to be a better predictor of teacher's improved perceptions of their ability to adapt instruction for students with IEPs than years of experience teaching such students.” (p. 8) However, upon examining the categories, participants were mostly desirous of more information. In a few instances, such as Kathryn's and Aurora's, the instructor attempted to engage or accommodate a student who needed to be helped, but did not feel successful afterwards. Bandura (1977) notes that failures tend to lower mastery expectations, but can be raised again through repeated successes. Participants expressed wanting broader and deeper knowledge about how to accommodate students with disabilities and, beyond that, help students who are struggling. This feeling of inadequacy speaks to a need for timely training or, as Goldstein and Ford (2002) posit, "an intervention into an organization" (p. 25). This finding informs the Evaluation Phase of the ADDIE model and provides fodder for the Analysis Phase of future training. Future training may need to address these feelings of inadequacy by providing participants with more information and mastery experiences early in the semester. This "just-in-time" training could allow instructors to already have appropriate resources available to them if a student who needs accommodation enrolls in their class.

Participants also viewed the training through the lens of their students. Many participants shared the theme of increased empathy and understanding. Some participants expressed that they could see the disability as "not the student's fault" and used more patience when working with 
students with disabilities, while other participants indicated that they would choose not to "baby" students with disabilities, but would encourage them in course work. Both categories are encouraging as much research on students with disabilities indicates that teachers often assign blame to students with disabilities (Boyle, 2016) or try to help by coddling them (Abdalla \& St. Louis, 2012). The theme of increased empathy and understanding was juxtaposed with the theme of future concern. Jessie's case, for example, shows that instructors experienced uncertainty and worry about how to accommodate behavioral issues in the classroom. Some participants, like Ashley, have not experienced a student with a disability in their classroom, but attending the training made them anxious. For these teachers, fear of future interactions outweighed a sense of self-efficacy. Future research should be conducted to determine why knowledge about accommodating students might produce anxiety in some teachers and not others. Specifically, future research should continue to examine disabilities through the lens of attribution theory. As some instructors emphasized the external nature of disabilities, it would be interesting to examine if instructors who view disabilities as biological have less anxiety and more empathy compared to instructors who view disabilities as internal or psychological.

Finally, all focus groups discussed the logistics of the training, resulting in three main themes: desiring specific resources, desiring extended time, and valuing expert insight. Instructors wanted immediate access to resources for their students. Because participants were given so much information over the two weeks of teacher training, they felt like the needed a comprehensive list of resources to best accommodate students. Some participants like Chris also stated that they wanted to have more interaction with students with disabilities and hear about their experiences. This finding is encouraging because research shows that individuals who are familiar with people with disabilities often have more positive attitudes about accommodating 
people with disabilities (e.g., Brockelman et al., 2006; Boyle, 2016). Across all groups, participants said that they wanted extended training. Incorporating up to eight hours of training throughout the school year could potentially allow instructors to feel twice as capable as they did previously (Kosko \& Wilkins, 2009). Future research needs to be conducted on the effect, and potential benefit, of mini-lessons for busy teachers. Lastly, participants stated that they valued input from people they found credible. The training session involved brief presentations from experts, which were well received by the participants. These messages of " you can accommodate students" combined with education and practical steps would speak to Bandura's (1997) description of social persuasion.

\section{Strengths and Limitations}

This study had several strengths, as well as key limitations. Additionally, this study revealed several areas for future research. A strength of this study was the use of both quantitative and qualitative data, which allowed for breadth and depth of understanding and validation. For example, the quantitative results concerning self-efficacy were used to corroborate the qualitative findings. This triangulation process allowed me to use multiple techniques to view the findings from various vantage points. The role I played as the moderator served as both a strength and a limitation. Because of my intimacy and familiarity with the instructors and the training content, I was able to utilize my background knowledge on the topic (Krueger, 1988) and was able to follow the unique language and flow of the conversation without confusion. A moderator unfamiliar with the topic may have had several questions and needed more explanation about the conversations regarding disabilities. Because of my rapport with the focus groups, I could guide the conversation back on track when it strayed without participants losing enthusiasm for the topic. While my intimacy with this topic and the 
participants provided several opportunities, it may have also served as a limitation. Krueger (1988) warns that participants who work together may be selective in what they say around other in-group members and may not feel comfortable fully expressing their opinions. Since I served as the moderator, it is possible participants may have felt a lack of freedom because of my presence or the presence of other teachers. I did, however, follow Krueger's suggestions to focus on creating a nonthreatening environment and emphasizing that their responses would not change their relationship with the university. In future session, an assistant moderator to ask additional questions and probe for depth would be beneficial (Krueger, 1988). This would also help to curb another limitation, which was over-familiarity with the topic. Because participants and myself were all knowledgeable about student accommodations, more broad conversations that could have yielded different results were missed. A multi-school approach may be helpful, where participants from several universities are trained, and then sorted into focus groups with strangers.

A multi-school approach would help address another main limitation, which was the sample size of this study. At the onset of this study I knew that the sample would be underpowered because the university where this study took place only trains a certain number of GTAs per year, thus acquiring more GTAs for this study was not plausible. By training instructors at multiple universities, researchers would be able to better assess the attributions and attitudes of instructors. Additionally, using the ADDIE model with a larger population could allow researchers to evaluate overarching needs in the higher education system regarding disability training. While this study assessed the needs of the basic course at one university, it would be interesting for researchers to determine gaps in accommodation knowledge across multiple schools in order to design and develop more honed instructional strategies for 
implementing training to multiple audiences. Another limitation was the availability of posttest responses from instructors who took the training. Even though fourteen participants submitted a posttest, I was unable to use all the results because some participants had not included a matching identification number to allow me to identify their pretest. Future studies should consider alternate methods of matching pretest and posttest scores. Perhaps allowing participants to choose their own unique identification number (instead of specifying what the number should be) would help participants remember it. An additional limitation of this study was the use of Likert-type questions to assess instructor views on the root cause of stuttering. In this study, participants were asked separate questions to indicate whether they believed the cause of stuttering was psychological, biological, or a combination of psychological and biological factors. Several participants indicated that they believed the cause was psychological, biological, and a combination. Instead of using Likert-type questions, future studies should use radio buttons to only allow participants to choose one option.

Finally, the creation of the training was a strength of this study. By using the ADDIE model to assess the needs of the campus, the course, and the instructors, I was able to create a product that can be used for years to come. This thesis allowed for a thorough examination of the Evaluation Phase, which is a step often overlooked in the ADDIE model (Goldstein \& Ford, 2002). While I constantly evaluated the training during each phase and made appropriate changes to highlight the goal, outcomes, and objectives of the training, the final Evaluation Phase assessed in the quantitative and qualitative results revealed specific opportunities for growth. Adjustments can now be made to the material in order to hone the training and potentially expand it to other universities. Additionally, the development of this training provided the 
groundwork for the creation of further training sessions about other disabilities pertinent to the basic communication course classroom.

\section{Implications}

\section{Implications for Educators}

This study has implications for instructors as well as program directors. One of the most important findings in this study is that instructors want more information about how to interact with a growing body of diverse students. While some of these findings are particularly salient for students who stutter, the overarching messages about examining knowledge, attributions, and attitudes can be applied to all students, particularly students who fall outside of the "norm." As students with disabilities may be more likely to "slip through the cracks" and suffer from lower graduation rates (Zhang et al., 2010) it is important for program directors to assess how the knowledge and attitudes of their instructors may play a part in the academic success (or failure) of their students. Additionally, it is important for instructors to assess their own preconceived notions about students with disabilities. This study's focus on attribution theory explains why instructors should engage in self-reflection about why they may have specific attitudes regarding their students. They might find that beliefs about students stem from their interpretation of a student's behavior as "controllable" when it may not be.

Additionally, this study makes a strong case for program directors to build key partnerships with other invested groups on and off campus. This study utilized experts in the fields of Speech Language Pathology, disability services, and the basic communication course to fill gaps in knowledge that the other departments lacked. By coming together to create the training curriculum, both the basic course program and disability services office could accomplish their goal of preparing instructors in how to accommodate students with disabilities. 
Disability services can play an essential role in providing support and increasing faculty knowledge about the provision of accommodations (Bourke, Strehorn, \& Silver, 2000). However, program directors can also play an important part in informing disability services about their field. While disability services may often work with professionals to develop accommodations for a student with a disability, it is also advantageous for the program director to be involved in these conversations as they can provide knowledge about the specific requirements of their course. For example, in this study, conversations between the SLP, disability services office, and basic course director uncovered further accommodations for students who stutter. While extended time on a speech is a standard accommodation, these conversations showed that other potential accommodations for students who stutter may be to have them read their speech directly off an outline or to allow them to sit down while presenting. By providing the SLP and disability services coordinator with more details about speech requirements, we could develop potential accommodations that had not been utilized previously. Program directors should be encouraged to have conversations with the disability services office at their university to develop creative solutions for accommodations in their specific courses.

\section{Implications for Training}

Trainers can also play a significant role in the education that university instructors receive. It is important for trainers to note that instructors may want to provide accommodations for their students, and even have positive attitudes about accommodating students with disabilities, yet, as Fishbein and Ajzen (2010) suggest, attitudes and intentions do not necessarily predict behavior. Instead, situational factors, environmental constraints and skill ability can influence actions (Fishbein \& Ajzen, 2010). In the case of students who stutter, basic course instructors may think that they have giving beneficial advice (such as "just take a deep breath" or 
"slow down"), when, in reality, these comments may actually be seen as unconstructive and create a more negative experience for PWS (Butler, 2013; Hearne, Packman, Onslow, \& Quine, 2008). This study has made the case to provide increased training for university instructors about how to accommodate students with disabilities. Instructors who received training reported increased self-efficacy in knowing how to accommodate PWS and the qualitative results revealed that instructors wanted more training in regard to other disabilities as well. Additionally, training opportunities could expand beyond disabilities to also instructors in how to accommodate students from other potentially at-risk groups, such as ESL students.

One shortcoming of this study was the amount of time allotted to train instructors. While this hour and a half training session had positive effects, teachers who receive extended training experience higher levels of self-efficacy (Kosko \& Wilkins, 2009); therefore, as Drew explains in the qualitative data, trainers should develop mini-lessons for instructors throughout the semester. This may allow teachers to retain more information and relate content to the experiences they have during the school year. Additionally, trainers should not only focus on how to accommodate students, but why students with disabilities must be accommodated as faculty who are more knowledgeable about legal requirements may be more willing to provide accommodations (Rao \& Gartin, 2003). Like program directors, trainers should develop partnerships with key experts. Individuals are more accepting of information if they perceive it is coming from a specialist (Margolis \& McCabe, 2006; Pfitzner-Eden, 2016b), so trainers should seek out experts who can speak to the topic of student accommodation. This may include representatives from a disability services office, a medical professional, or perhaps even a student who has received accommodations from the university. 


\section{Implications for Future Research}

Participants provided ample information about future research. The most accessible is the possibility of creating training programs that serve as "mini-lessons" and then presenting those to instructors throughout the year. At the university where this study took place, incoming GTAs are required to attend weekly on-going instructional training for several months after the summer training session. This weekly gathering could serve as fertile ground for further instruction about accommodating students with disabilities. These mini-lessons would allow trainers to develop the evaluation process throughout the year and make necessary adjustments as they receive feedback from instructors. Future research should focus on the impact of extended time on participant self-efficacy. Mini-lessons may also help to address key findings from the focus groups, specifically, instructor feelings of inadequacy regarding students with disabilities beyond stuttering. Instructors indicated that feelings of inadequacy stemmed from a lack of resources and knowledge. This study speaks to the need for future research regarding instructors' knowledge, attributions, attitudes, and self-efficacy for a wider range of disabilities than just communicative disabilities. Mental disabilities such as anxiety, depression, and ADD/ADHD were prominent topics in each focus group because they affect a significant portion of the student population. Future research should focus on developing and conducting training sessions for instructors on these topics, as specific instructional strategies for managing various disabilities can provide trainers with opportunities to increase instructor self-efficacy. Furthermore, future research should examine the perspectives that students have of teachers who have received accommodation training. It would be interesting to examine if students perceive that teachers have better attitudes or increased self-efficacy in the classroom after completing training, and how instructor accommodation influences student learning and the classroom climate. 
Additionally, future research should examine the influence a training session about student accommodations may have on instructor attitudes and attributions. Because of the underpowered sample size, I was unable to determine if instructors who attribute the cause of stuttering to psychological factors have more negative attitudes about PWS than instructors who attribute the cause to biological factors. Additionally, I was unable to determine the impact that the training had on instructor attitudes. However, the focus group data revealed that instructors did seem to emphasize the external nature of disabilities and the influence of the training on increasing their empathy toward students with disabilities. Because of the discrepancy between the quantitative and qualitative data, future research should focus on these two areas as a change in attribution may lead to a change in attitude.

Finally, future research should be conducted to determine the effect of the training with other populations and in other contexts. It may be beneficial to conduct this training in other arenas as stuttering can have an influence on the social, academic, and vocational realms for PWS. While this study focused on the perceptions of basic communication course instructors, future studies may focus on business owners or human resource executives, leaders of social clubs on campuses (such as sororities and fraternities), or university faculty and staff beyond the basic course classroom. In order to provide timely training, it may also be beneficial to examine the use of web-based content (such as multiple webinars) to develop the training for multiple audiences. Researchers could adapt the ADDIE model to implement content that could be more far-reaching.

\section{Conclusion}

The findings from this study are exciting because they show that instructors want to be more knowledgeable about accommodating students with disabilities, and feel a greater sense of 
self-efficacy when they have appropriate resources. Although this training examined the perceptions of basic communication course instructors, findings from this study could be transferable to other general education course teachers, as well as university faculty and staff. Similarly, other university-centered organizations such as Greek Life and student-run clubs may find benefit from training their participants and examining attitudes about students with disabilities.

Life as a teacher can be full of challenges, especially when teaching a diverse student body. Many students expressed this sentiment during the focus groups. However, teachers also identified the value that they took from learning about disability accommodation. Mike identified that even though the process of training to become an instructor was overwhelming, having the knowledge, resources, and community he needs to accommodate his students made him feel successful. He explained, “...the big take-away was, 'you have a resource, we're here to help ya', and that's what I needed to hear at that time." 


\section{REFERENCES}

Abdalla, F. A., \& St. Louis, K. O. (2012). Arab school teachers' knowledge, beliefs and reactions regarding stuttering. Journal of Fluency Disorders, 37, 54-69. doi: 10.1016/j.jfludis.2011.11.007

Abreu, M., Hillier, A., Frye, A., \& Goldstein, J. (2016). Student experiences utilizing disability support services in a university setting. College Student Journal, 50(3), 323-328.

Adriaensens, S., Beyers, W., \& Struyf, E. (2015). Impact of stuttering severity on adolescents' domain-specific and general self-esteem through cognitive and emotional mediating processes. Journal of Communication Disorders, 58, 43-57. doi: 10.1016/j.jcomdis.2015.10.003

Al-Khaledi, M., Lincoln, M., McCabe, P., Packman, A., \& Alshatti, T. (2009). The attitudes, knowledge and beliefs of Arab parents in Kuwait about stuttering. Journal of Fluency Disorders, 34, 44-59. doi: 10.1016/j.jfludis.2009.02.003

Allen, W. C. (2006). Overview and evolution of the ADDIE training system. Advances in Developing Human Resources, 8(4), 430-441. doi: 10.1177/1523422306292942

Americans with Disabilities Act of 1990 (ADA), 42 U.S.C. $§ 12101$ et seq.

Arnold, H. S., Li, J., \& Goltl, K. (2015). Beliefs of teachers versus non-teachers about people who stutter. Journal of Fluency Disorders, 43, 28-39. doi: 10.1016/j.jfludis.2014.12.001

Assessing the Basic Course. (n.d.). Retrieved from http://dev.natcom.org/teachingandlearning/basiccourse/assessing/

Bandura, A. (1997). Self-efficacy: The exercise of control. New York, NY: W.H. Freeman and Company. 
Bandura, A. (1977). Self-efficacy: Toward a unifying theory of behavioral change. Psychological Review, 84(2), 191-215. doi:10.1037//0033-295x.84.2.191

Beatty, M. L. (2013). Not a bad idea: The increasing need to clarify free appropriate public education provisions under the individuals with disabilities education act. Suffolk University Law Review, 46(2), 529-550.

Beebe, S. A., Mottet, T. P., \& Roach, K. D. (2012). Training and development: Communicating for success $\left(2^{\text {nd }}\right.$ ed.). New York, NY: Pearson.

Beech, H. R., \& Fransella, F. (1968). Research and experimenting in stuttering. Headington Hill Hall, Oxford: Pergamon Press Ltd.

Beilke, J. R. \& Yssel, N. (1999). The chilly climate for students with disabilities in higher education. College Student Journal, 33(3), 1.

Bingham, S. G., Carlson, R. E., Dwyer, K. K., \& Prisbell, M. (2009). Student misbehaviors, instructor responses, and connected classroom climate: Implications for the basic course. Basic Communication Course Annual, 21, 30-39.

Blood, G. W., \& Blood, I. M. (2004). Bullying in adolescents who stutter: Communicative competence and self-esteem. Contemporary Issues in Communication Science and Disorders, 31, 69-79.

Blood, G. W., Blood, I. M., Tellis, G., \& Gabel, R. (2001). Communication apprehension and self-perceived communication competence in adolescents who stutter. Journal of Fluency Disorders, 26, 161-178. doi: 10.1016/s0094-730x(01)00097-3

Blood, G. W., Blood, I. M., Tellis, G., \& Gabel, R. M. (2003). A preliminary study of selfesteem, stigma, and disclosure in adolescents who stutter. Journal of Fluency Disorders, 28(2), 143-159. doi: 10.1016/S0094-730X(03)00010-X 
Bloodstein, O. (1993). Stuttering: The search for a cause and cure. Boston, MA: Allyn and Bacon.

Bourke, A. B., Strehorn, K. C., \& Silver, P. (2000). Faculty members' provision of instructional accommodations to students with LD. Journal of Learning Disabilities, 33(1), 26-32.

Boyle, M. (2014). Understanding perceptions of stuttering among school-based speech-language pathologists: An application of attribution theory. Journal of Communication Disorders, 52, 143-155. doi: 10.1016/j.jcomdis.2014.06.003

Boyle, M. (2016). The impact of causal attribution on stigmatizing attitudes toward a person who stutters. Journal of Communication Disorders, 60, 14-26. doi:

10.1016/j.jcomdis.2016.02.002

Brady, K., \& Woolfson, L. (2008). What teacher factors influence their attributions for children's difficulties in learning? British Journal of Educational Psychology, 78, 527-544. doi: $10.1348 / 000709907 X 268570$

Braithwaite, C. A., \& Braithwaite, D. O. (1991). Instructional communication strategies for adapting to a multicultural introductory course. Basic Communication Course Annual, 3, 1-16.

Bray, M. A., Kehle, T. J., Lawless, K. A., \& Theodore, L. A. (2003). The relationships of selfefficacy and depression to stuttering. American Journal of Speech-Language Pathology, $12,425-431$.

Brockelman, K. F., Chadsey, J. G., \& Loeb, J. W. (2006). Faculty perceptions of university students with psychiatric disabilities. Psychiatric Rehabilitation Journal, 30(1), 23-30.

Büchel, C., \& Sommer, M. (2004). What causes stuttering? PLoS Biology, 2(2), 159-163. doi: 10.1371/journal.pbio.0020046 
Butler, C. (2013). 'University?...hell no!': Stammering through education. International Journal of Educational Research, 59, 57-65. doi: 10.1016/j.jjer.2013.03.002

Carroll, A., Forlin, C., \& Jobling, A. (2003). The impact of teacher training in special education on the attitudes of Australian preservice general educators towards people with disabilities. Teacher Education Quarterly, 30(3), 65-79.

Common core state standards initiative. (2016). Retrieved from http://www.corestandards.org/ELA-Literacy/SL/6/

Corbin, J., \& Strauss, A. (2015). Basics of qualitative research: Techniques and procedures for developing grounded theory $\left(4^{\text {th }}\right.$ ed.). Thousand Oaks, CA: Sage Publications, Inc.

Craig, D. (2006). Revising pedagogical strategies in large enrollment general education courses. Basic Communication Course Annual, 18, 244-260.

Craig, A., Blumgart, E., \& Tran, Y. (2009). The impact of stuttering on the quality of life in adults who stutter. Journal of Fluency Disorders, 34, 61-71. doi:10.1016/j.jfludis.2009.05.002

Craig, A., \& Tran, Y. (2014). Trait and social anxiety in adults with chronic stuttering: Conclusions following meta-analysis. Journal of Fluency Disorders, 40, 35-43. doi: 10.1016/j.jfludis.2014.01.001

Craig, A., \& Tran, Y. (2015). The psychological impact of chronic stuttering in adults. In Santiago, D (Ed.), Stuttering: Risk factors, public attitudes, and impact on psychological well-being (37-56). New York, NY: Nova Science Publishers, Inc.

Crowe, T. A., \& Walton, J. H. (1981). Teacher attitudes toward stuttering. Journal of Fluency Disorders, 6, 163-174. doi: 10.1016/0094-730x(81)90013-9 
Curtis, D. B., Winsor, J. L., \& Stephens, R. D. (1989). National preferences in business and communication education. Communication Education, 38(1), 6-14. doi:

Daniels, D. E., Panico, J., \& Sudholt, J. (2011). Perceptions of university instructors toward students who stutter: A quantitative and qualitative approach. Journal of Communication Disorders, 44, 631-639. doi: 10.1016/j.jcomdis.2011.07.002

DeSimone, J. R., \& Parmar, R. S. (2006). Middle school mathematics teachers' beliefs about inclusion of students with learning disabilities. Learning Disabilities Research \& Practice, 21(2), 98-110. doi: 10.1111/j.1540-5826.2006.00210.x

DeVellis, R. F. (2003). Scale development: Theory and applications. Thousand Oaks, CA: Sage Publications, Inc.

Drayna, D., \& Kang, C. (2011). Genetic approaches to understanding the causes of stuttering. Journal of Neurodevelopmental Disorders, 3, 374-380.

Dunbar, N. E., Brooks, C. F., \& Kubicka-Miller, T. (2006). Oral communication skills in higher education: Using a performance-based evaluation rubric to assess communication skills. Innovative Higher Education, 31(2), 115-128. doi: 10.1007/s10755-006-9012-x

Eckes, S. E., \& Ochoa, T. A. (2005). Students with disabilities: Transitioning from high school to higher education. American Secondary Education, 33(3), 6-20.

Eichhorn, L. (1999). Major litigation activities regarding major life activities: The failure of the disability definition in the Americans with disabilities act of 1990. North Carolina Law Review, 77(4), 1405-1478.

Ezrati-Vinacour, R., \& Levin, I. (2004). The relationship between anxiety and stuttering: A multidimensional approach. Journal of Fluency Disorders, 29, 135-148. doi: 10.1016/j.jfludis.2004.02.003 
Fasset, D. L., \& Warren, J. T. (2008). Pedagogy of relevance: A critical communication pedagogy agenda for the 'basic' course. Basic Communication Course Annual, 20, 1-34.

Fishbein, I., \& Ajzen, M. (2010). Predicting and changing behavior: The reasoned action approach. New York, NY: Taylor and Francis Group, LLC.

Fogliasso, C. E., \& Hicks, J. (2012). The Americans with disabilities act: Legal requirements, ethical considerations. Franklin Business \& Law Journal, 1, 1-8.

Fotsch, P. (2008). Race and resistance in the communication classroom. Basic Communication Course Annual, 20, 197-230.

Franck, A. L., Jackson, R. A., Pimentel, J. T., \& Greenwood, G. S. (2003). School-age children's perceptions of a person who stutters. Journal of Fluency Disorders, 28, 1-15. doi: 10.1016/S0094-730X(03)00002-0

Glaser, B. G., \& Strauss, A. L. (1999). The discovery of grounded theory: Strategies for qualitative research. New Brunswick, NJ: Aldine Transaction.

Goals, outcomes, and objectives. (2017). In International Assembly for Collegiate Business Education. Retrieved from http://iacbe.org/oa-goals-outcomes-objectives.asp

Goldstein I. L., \& Ford K. (2002). Training in Organizations: Needs assessment, Development and Evaluation (4th ed.). Belmont, CA: Wadsworth.

Gotshall, C., \& Stefanou, C. (2011). The effects of on-going consultation for accommodating students with disabilities on teacher self-efficacy and learned helplessness. EducationIndianapolis Then Chula Vista, 132(2), 321-331.

Greer, M. (2014). The project manager's partner: A step-by-step guide to project management. Amherst, MA: HRD Press. 
Gustafson, K. L., \& Branch, R. M. (2002). What is instructional design?. Reiser, R. A., \& Dempsey, J. V. (Eds.). Upper Saddle River, NJ: Merrill Prentice Hall.

Hannum, W. (2001). COM 435: Overview of ADDIE and ISD. Retrieved from http://www.soe.unc.edu/ISD/index.html

Hao, R. N. (2010). (Re)constructing ELL and international student identities in the oral communication course. Basic Communication Course Annual, 22, 125-152.

Hartley, M. T. (2010). Increasing resilience: Strategies for reducing dropout rates for college students with psychiatric disabilities. American Journal of Psychiatric

Rehabilitation, 13(4), 295-315. doi:10.1080/15487768.2010.523372

Hastings, R. P., Hewes, A., Lock, S., \& Witting, A. (1996). Do special educational needs courses have any impact on student teachers' perceptions of children with severe learning difficulties?. British Journal of Special Education, 23(3), 139-144. doi: 10.1111/j.14678578.1996.tb00965.x

Hearne, A., Packman, A., Onslow, M., \& Quine, S. (2008). Stuttering and its treatment in adolescence: The perceptions of people who stutter. Journal of Fluency Disorders, 33, 81-98. doi: 10.1016/j.jfludis.2008.01.001

Heider, F. (1958). The Psychology of Interpersonal Relations. Hillsdale, New Jersey: Lawrence Erlbaum Associates.

History - Brown v. Board of Education Re-enactment. (n.d.). Retrieved from http://www.uscourts.gov/educational-resources/educational-activities/history-brown-vboard-education-re-enactment 
Hodis, G. M., \& Hodis, F. A. (2013). Static and dynamic interplay among communication apprehension, communicative self-efficacy, and willingness to communicate in the communication course. Basic Communication Course Annual, 25, 70-125.

Housley Gaffney, A. L., \& Frisby, B. N. (2013). A new hybrid: Students' extensions of integrated communication content. Basic Communication Course Annual, 25, 207-244.

Hugenberg, L. W., \& Moyer, B. S. (1997). A commentary: The basic communication course, general education and assessment. Basic Communication Course Annual, 9, 160-179.

Hughes, S., Gabel, R., Irani, F., \& Schlagheck, A. (2010a). University students' perceptions of the life effects of stuttering. Journal of Communication Disorders, 43, 45-60. doi: 10.1016/j.jcomdis.2009.09.002

Hughes, S., Gabel, R. M., Irani, F., \& Schlagheck, A. (2010b). University students' explanations for their descriptions of people who stutter: An exploratory mixed model study. Journal of Fluency Disorders, 35, 280-298. doi: 10.1016/j.jfludis.2010.05.006

Hulit, L. M. (2004). Straight talk on stuttering: Information, encouragement, and counsel for stutterers, caregivers, and speech-language clinicians ( $2^{\text {nd }}$ ed.). Springfield, IL: Charles C. Thomas Publisher, Ltd.

Hunt, S. K., Ekachai, D., Garard, D. L., \& Rust, J. H. (2001). Students’ perceived usefulness and relevance of communication skills in the basic course: Comparing university and community college students. Basic Communication Course Annual, 13, 1-22.

Hunt, S. K., Novak, D. R., Semlak, J. L., \& Meyer, K. R. (2005). Synthesizing the first 15 years of the basic communication course annual: What research tells us about effective pedagogy. Basic Communication Course Annual, 17, 1-42. 
Hunt, S. K., Simonds, C. J., \& Simonds, B. K., (2009). Uniquely qualified, distinctively competent: Delivering $21^{\text {st }}$ century skills in the basic course. Basic Communication Course Annual, 21, 1-29.

Individuals with Disabilities Education Act of 1990 (IDEA), 20 U.S.C. SS 1400 et seq.

Introduction to the ADA. (n.d.). Retrieved from https://www.ada.gov/ada_intro.htm

Irani, F., \& Gabel, R. (2008). Schoolteachers' attitudes toward people who stutter: Results of a mail survey. Canadian Journal of Speech-Language Pathology and Audiology, 32(3), 129-134.

Iverach, L., \& Rappe, R. M. (2014). Social anxiety disorder and stuttering: Current status and future directions. Journal of Fluency Disorders, 40, 69-82. doi: 10.1016/j.jfludis.2013.08.003

Jager, L., \& Denessen, E. (2015). Within-teacher variation of causal attributions of low achieving students. Social Psychology of Education, 18(3), 517-530. doi: $10.1007 /$ s $11218-015-9295-9$

Johnson, J. K., (2008). The visualization of the twisted tongue: Portrayals of stuttering in film, television, and comic books. The Journal of Popular Culture, 41(2), 245-261. doi: 10.1111/j.1540-5931.2008.00501.x

Johnson, J. R., Pliner, S. M., \& Burkhart, T. (2002). D/deafness and the basic course: A case study of universal instructional design and students who are $\mathrm{d} /$ deaf in the (aural) communication classroom. Basic Communication Course Annual, 14, 211-241.

Joslyn, M. R., \& Haider-Markel, D. P. (2013). The politics of causes: Mass shootings and the cases of the Virginia tech and Tucson tragedies. Social Science Quarterly, 92(2), 410423. doi: 10.1111/j.1540-6237.2012.00894.x 
Kalinowski, J. S., Lerman, J. W., \& Watt, J. (1987). A preliminary examination of the perceptions of self and others in stutterers and nonstutterers. Journal of Fluency Disorders, 12(5), 317-331. doi: 10.1016/0094-730X(87)90030-1

Katsiyannis, A., Zhang, D., Landmark, L., \& Reber, A. (2009). Postsecondary education for individuals with disabilities: Legal and practical considerations. Journal of Disability Policy Studies, 20(1), 35-45. doi: 10.1177/1044207308324896

Kirkpatrick, J., \& Kirkpatrick, W. K. (2009). The Kirkpatrick four levels: A fresh look after 50 years 1959-2009. Retrieved from http://www.kirkpatrickpartners.com/Portals/0/Resources/Kirkpatrick\%20Four\%20Levels \%20white\%20paper.pdf

Klein, J. F., \& Hood, S. B. (2004). The impact of stuttering on employment opportunities and job performance. Journal of Fluency Disorders, 29, 255-273. doi: 10.1016/j.jfludis.2004.08.001

Klompas, M., \& Ross, E. (2004). Life experiences of people who stutter, and the perceived impact of stuttering on quality of life: Personal accounts of South African individuals. Journal of Fluency Disorders, 29, 275-305. doi: 10.1016/j.jfludis.2004.10.001

Kluger, R. (2004). Simple justice: The history of Brown v. board of education and Black America's struggle for equality. New York, NY: Vintage Books.

Kosko, K. W., \& Wilkins, J. L. M. (2009). General educators' in-service training and their selfperceived ability to adapt instruction for students with IEPs. Professional Educator, $33(2), 1-10$.

Kraaimaat, F. W., Vanryckeghem, M., \& Van Dam-Baggen, R. (2002). Stuttering and social anxiety. Journal of Fluency Disorders, 27, 319-331. 
Kramer, M. W., \& Hinton, J. S. (1996). The differential impact of a basic public speaking course on perceived communication competencies in class, work, and social contexts. Basic Communication Course Annual, 8, 1-25.

Krewson, T. (2016). The conflict between preserving the rights of students with disabilities and promoting safe schools: Will the procedural safeguards of the individuals with disabilities education act survive the era of school violence?. University of Toledo Law Review, 47, $515-552$.

Krueger, R. A. (1988). Focus groups: A practical guide for applied research. Newbury Park, CA: Sage Publications, Inc.

LeBlanc Farris, K., Houser, M. L., \& Wotipka, C. D. (2013). Assessing student public speaking competence in the hybrid basic communication course. Basic Communication Course Annual, 25, 161-206.

Lindlof, T. R., \& Taylor, B. C. (2011). Qualitative communication research methods $\left(3^{\text {rd }}\right.$ ed.). Thousand Oaks, CA: Sage Publications, Inc.

Margolis, H., \& McCabe, P. P. (2006). Improving self-efficacy and motivation: What to do, what to say. Intervention in School and Clinic, 41(4), 218-227.

Marshall, J., Ralph, S., \& Palmer, S. (2002). 'I wasn't trained to work with them': Mainstream teachers' attitudes to children with speech and language difficulties. International Journal of Inclusive Education, 6(3), 199-215. doi: 10.1080/13603110110067208

Mayfield, M. (2011). Creating training and development programs: Using the ADDIE method. Developing and Learning in Organizations: An International Journal, 25(3), 19-22. doi: $10.1108 / 14777281111125363$ 
Meredith, G., Packman, A., \& Marks, G. (2012). Stuttering, disability and the higher education sector in Australia. International Journal of Speech-Language Pathology, 14(4), 370376. doi: 10.3109/17549507.2012.683809

Miller, K. J., Wienke, W. D., \& Savage, L. B. (2000). Elementary and middle/secondary educator's pre and post training perceptions of ability to instruct students with disabilities. Rural Special Education Quarterly, 19(3-4), 3-14.

Morgan, D. L. (1997). Focus groups as qualitative research $\left(2^{\text {nd }}\right.$ ed.). Thousand Oaks, CA: Sage Publications, Inc.

Morgan, D. L. (1998). The focus group guidebook. Thousand Oaks, CA: Sage Publications, Inc.

Morreale, S. P., Hanna, M. S., Berko, R. M., \& Gibson, J. W. (1999). The basic communication course at U.S. colleges and universities: VI. Basic Communication Course Annual, 11, 136.

Morreale, S. P., \& Pearson, J. C. (2008). Why communication education is important: The centrality of the discipline in the $21^{\text {st }}$ century. Communication Education, 57(2), 224-240.

Morreale, S., Hugenberg, L., \& Worley, D. (2006). The basic communication course at U.S. colleges and universities in the $21^{\text {st }}$ century: Study VII. Communication Education, 55(4), 415-437. doi: 10.1080/03634520600879162

Morreale, S. P., Myers, S. A., Backlund, P. M., \& Simonds, C. J. (2016). Study IX of the basic communication course at two-and four-year U.S. colleges and universities: A reexamination of our discipline's “front porch". Communication Education, 65(3), 338355. doi: $10.1080 / 03634523.2015 .1073339$ 
Morreale, S. P., Osborn, M. M., \& Pearson, J. C. (2000). Why communication is important: A rationale for the centrality of the study of communication. Journal of the Association for Communication Administration, 29(1), 1-25.

Morreale, S. P., Worley, D. W., \& Hugenberg, B. (2010). The basic communication course at two-and four-year U.S. colleges and universities: Study VIII- the $40^{\text {th }}$ anniversary. Communication Education, 59(4), 405-430. doi: 10.1080/03634521003637124

Mottet, T. P. (2006). Proficient enough?. Retrieved from http://dev.natcom.org/CommCurrentsArticle.aspx?id=1122

National Stuttering Association. (2017). General information. Retrieved from http://www.westutter.org/what-is-stuttering/

National Center for Education Statistics. (n.d.). Students with disabilities. Retrieved from https://nces.ed.gov/fastfacts/display.asp?id=60

Newburger, C. (1994). Determining reasonable accommodations for the learning impaired: New issues for able-bodied communication administrators. Journal of the Association for Communication Administration, 3, 181-184.

Nicastro, F. (2000) Americans with disabilities act: Determining which learning disabilities qualify for reasonable accommodations. Journal of Legislation, 26(2), 355-376.

Osborne, D., \& Weiner, B. (2015). A latent profile analysis of attributions for poverty: Identifying response patterns underlying people's willingness to help the poor. Personality and Individual Differences, 85, 149-154. doi: 10.1016/j.paid.2015.05.007

People with disabilities and postsecondary education-position paper. (2003). In National Council on Disability. Retrieved from http://www.ncd.gov/publications/2003/people-disabilitiesand-postsecondary-education-position-paper 
Peterson, C. (2003). Bringing ADDIE to life: Instructional design at its best. Journal of Educational Multimedia and Hypermedia, 12(3), 227-241.

Pfitzner-Eden, F. (2016a). I feel less confident so I quit? Do true changes in teacher self-efficacy predict changes in preservice teachers' intention to quit their teaching degree?. Teaching and Teacher Education, 55, 240-254. doi:10.1016/j.tate.2016.01.018

Pfitzner-Eden, F. (2016b). Why do I feel more confident? Bandura's sources predict preservice teachers' latent changes in teacher self-efficacy. Frontiers in Psychology, 7, 1-16. doi: 10.3389/fpsyg.2016.01486

Rao, S., \& Gartin, B. C. (2003). Attitudes of university faculty towards accommodations to students with disabilities. Journal for Vocational Special Needs Education, 25(2), 47-54.

Rieber, R. W., \& Wollock, J. (1977). The historical roots of the theory and therapy of stuttering. Journal of Communications Disorders, 10, 3-24.

Robotham, D. (2003). Learning and training: Developing the competent learner. Journal of European Industrial Training, 27(9), 473-480. doi: 10.1108/03090590310506487

Rothstein, L. (2015). Americans with disabilities act and higher education 25 years later: An update on the history and current disability discrimination issues for higher education. Journal of College and University Law, 41(3), 531-590.

Ruppar, A. L., Neeper, L. S., \& Dalsen, J. (2016). Special education teachers' perceptions of preparedness to teach students with severe disabilities. Research and Practice for Persons with Severe Disabilities, 41(4), 273-286. doi: 10.1177/1540796916672843 
Sanford, C. Newman, L., Wagner, M., Cameto, R., Knokey, A. M., \& Shaver, D. (2011). The post-high school outcomes of young adults with disabilities up to 6 years after high school: Key findings from the national longitudinal transition study-2 (NLTS2). Menlo Park, CA: SRI International.

Schreyer Institute for Teaching Excellence. (2017). Penn state definitions of goals, objectives and outcomes. Retrieved from http://www.schreyerinstitute.psu.edu/assessment/definition

Scott, L., Guitar, C., \& Chemla, K. (2010). Stuttering: Straight talkfor teachers $\left(3^{\text {rd }}\right.$ ed.). Memphis, TN: The Stuttering Foundation.

Section 504 of the Rehabilitation Act of 1973, 29 U.S.C. $§ 794($ a) et seq.

Sermas, C. E., \& Cox, M. D. (1982). The stutterer and stuttering: Personality correlates. Journal of Fluency Disorders, 7, 141-158.

Sharma, U., Forlin, C., \& Loreman, T. (2008). Impact of training on pre-service teachers' attitudes and concerns about inclusive education and sentiments about persons with disabilities. Disability \& Society, 23(7), 773-785. doi: 10.1080/09687590802469271

Silverman, F. H. (2004). Stuttering and other fluency disorders ( $3^{\text {rd }}$ ed.). Long Grove, IL: Waveland Press.

Silverman, F. H., \& Paynter, K. K. (1990). Impact of stuttering on perception of occupational competence. Journal of Fluency Disorders, 15(2), 87-91. doi: 10.1016/0094730X(90)90035-Q

Simonds, C. J., Buckrop, J., Redmond, M., \& Hefferin, D. (2012). National Communication Association Resolution on the Role of Communication in General Education. Adopted by the NCA Legislative Assembly, November 17, 2012. 
Snyder, M. A. (1977). A psychodynamic approach to the theory and therapy of stuttering. Journal of Communication Disorders, 10(1-2), 85-88. doi: 10.1016/00219924(77)90018-1

Soodak, L. C., Podell, D. M., \& Lehman, L. R. (1998). Teacher, student, and school attributes as predictors of teachers' responses to inclusion. The Journal of Special Education, 31, 480497.

Stawser, M. G., Frisby, B. N., \& Kaufmann, R. (2017). Universal adaptation: The need to enhance accessibility in the basic course. Basic Communication Course Annual, 29, 9097.

Taliaferro, A., \& Pilkington Harris, N. (2014). The effects of a one-day workshop on physical educators' self-efficacy toward inclusion of students with autism. Palaestra, 28(3), 3843.

The Stuttering Foundation. (2017). FAQ. Retrieved from http://www.stutteringhelp.org/faq Tran, Y., Blumgart, E., \& Craig, A. (2011). Subjective distress associated with chronic stuttering. Journal of Fluency Disorders, 36, 17-26. doi: 10.1016/j.jfludis.2010.12.003

Turner, E. (2006) Learning that lasts. Industrial and Commercial Training, 38(3), 137-142. doi: $10.1108 / 00197850610659391$

U.S. Department of Education. (2015). The civil rights of students with hidden disabilities under Section 504 of the Rehabilitation Act of 1973. Retrieved from https://www2.ed.gov/about/offices/list/ocr/docs/hq5269.html Valenzano, J. M. (2013). Directing the winds of change: The basic course and general education. Basic Communication Course Annual, 25, 1-37. 
Van Borsel, J., Brepoels, M., \& De Coene, J. (2011). Stuttering, attractiveness and romantic relationships: The perception of adolescents and young adults. Journal of Fluency Disorders, 36, 41-50. doi: 10.1016/j.jfludis.2011.01.002

Vasek, D. (2005). Assessing the knowledge base of faculty at a private, four-year institution. College Student Journal, 39(2), 307-315.

Vaz, S., Wilson, N., Falkmer, M., Sim, A., Scott, M., Cordier, R., \& Falkmer, T. (2015). Factors associated with primary school teachers' attitudes towards the inclusion of students with disabilities. PLoS ONE, 10(8), 1-12. doi: 10.1371/journal.pone.0137002

Verderber, R. F. (1991). The introductory communication course: The public speaking approach. Basic Communication Course Annual, 3, 3-13.

Vishwanath, A. (2014). Negative public perceptions of juvenile diabetics: Applying attribution theory to understand the public's stigmatizing views. Health Communication, 29, 516526. doi: 10.1080/10410236.2013.777685

Wang, G. G., \& Wilcox, D. (2006). Training evaluation: Knowing more than is practiced. Advances in Developing Human Resources, 8(4), 528-539. doi: $10.1177 / 1523422306293007$

Whaley, B. B., \& Langlois, A. (1996). Students who stutter and the basic course: Attitudes and Communication Strategies for the college classroom. Basic Communication Course Annual, 8, 58-73.

Wilson, K., Getzel, E., \& Brown, T. (2000). Enhancing the post-secondary campus climate for students with disabilities. Journal of Vocational Rehabilitation, 14, 37-50.

Weiner, B. (1985). An attributional theory of achievement motivation and emotion. Psychological Review, 92(4), 548-573. doi: 10.1007/978-1-4612-4948-1_6 
Whitehead, A. L. (2014). Politics, religion, attribution theory, and attitudes toward same-sex unions. Social Science Quarterly, 95(3), 701-718. doi: 10.1111/ssqu.12085

World Health Organization. (2001). International classification of functioning, disability, and health. Geneva: World Health Organization.

Yaruss, J. S., \& Quesal, R. W. (2004). Stuttering and the international classification of functioning, disability, and health (ICF): An update. Journal of Communication Disorders, 37, 35-52. doi: 10.1016/S0021-9924(03)00052-2

Yeakle, M., \& Cooper, E. B. (1986). Teacher perceptions of stuttering. Journal of Fluency Disorders, 11, 345-359. doi: 10.1016/0094-730x(86)90022-7

Yell, M. L., Rogers, D., \& Rogers, E. L. (1998). The legal history of special education: What a long, strange trip it's been!. Remedial \& Special Education, 19(4), 219-228. doi: $10.1177 / 074193259801900405$

Zee, M., Koomen, H. M. Y., Jellesma, F. C., Geerlings, J., \& de Jong, P. F. (2016). Inter- and intra-individual differences in teachers' self-efficacy: A multilevel factor exploration. Journal of School Psychology, 55, 39-56. doi:10.1016/j.jsp.2015.12.003

Zhang, D., Landmark, L., Reber, A., Hsu, H., Kwok, O., \& Benz, M. (2010). University faculty knowledge, beliefs, and practices in providing reasonable accommodations to students with disabilities. Remedial and Special Education, 31(4), 276-286. doi:

$10.1177 / 0741932509338348$ 


\section{APPENDIX A: TRAINING GOAL, OUTCOMES, AND OBJECTIVES}

Goal: GTAs will develop more positive attitudes toward students with disabilities and will develop greater self-efficacy in how to accommodate them in the classroom.

\section{Outcomes:}

1. Outcome: At the end of the training session, GTAs should be able to demonstrate awareness of, and show sensitivity to, the stigma people who stutter (PWS) experience.

a. Objective: Attendees should be able to articulate the preconceived beliefs they held about PWS and explain the evolution of those beliefs.

i. Instructional Strategy: The opening activity will involve a group discussion asking GTAs to describe words they associate with PWS. At the end of the training, the GTAs will revisit the compiled list of words and explain what words they would keep, remove, or change.

b. Objective: Attendees should demonstrate a willingness to view students who stutter no differently than fluent students.

i. Instructional Strategy: The pre and post-test survey should show that after the training GTAs are more prone to agree with the following statements: "I believe this student can have any job he/she wants" and "I would act as if this student was speaking normally." GTAs should be less prone to agree with the following statements: "I believe this student is shy or fearful" and "I believe this student will have a lower level of academic performance than a non-stuttering student."

c. Objective: At the end of the training session, GTAs should feel more confident interacting with students who stutter.

i. Instructional Strategy: The pre and post-test survey should show that after the training GTAs are more prone to agree with the following statement: "I would feel comfortable interacting with this student" and less prone to agree with, "I would feel anxious interacting with this student."

2. Outcome: At the end of the training session, GTAs should be able to demonstrate awareness of, and show sensitivity to, students with disabilities as a whole.

a. Objective: Attendees should be able to articulate the value in accommodating students with various disabilities

i. Instructional Strategy: The closing activity will be a group discussion about what beliefs apply to PWS and students with disabilities as a whole

3. Outcome: At the end of the training session, GTAs should be more willing to engage all of their students in conversations about accommodating students with disabilities.

a. Objective: Attendees should be able to role-play the conversation they will have with their class on the first day of school about the university's disability policy, the process of registering, and why it is important.

i. Instructional Strategy: During the closing activity, the GTAs will have a group discussion about how to have this conversation, and then will share their ideas. 
4. Outcome: At the end of the training session, GTAs should feel a greater sense of selfefficacy and more confident about their access to resources.

a. Objective: Attendees should be able to identify on a survey their level of confidence regarding teaching students with disabilities at the end of the training versus their confidence level at the beginning of the training.

i. Instructional Strategy: The pre and post-test survey should show that after the training GTAs are more prone to agree with the following statement: "I would feel comfortable interacting with this student" and "I have the resources I need to accommodate this student."

ii. Instructional Strategy: The training will include a Q\&A time with both the SLP and the Student Access and Accommodation Services office in order for GTAs to answer any lingering questions or concerns.

iii. Instructional Strategy: At the end of the training, all GTAs will be provided with a handout listing do's and dont's about how to interact with PWS, and details about how to easily contact Student Access and Accommodation Services.

5. Outcome: At the end of the training session, GTAs should be able to state the causes and effects of stuttering, the varieties of stuttering, and the strategies for managing stuttering.

a. Objective: Attendees should be able to identify the difference between a biological and psychological root cause of verbal dysfluency.

i. Instructional Strategy: SLP will answer the question, "What causes stuttering?"

b. Objective: Attendees should be able to explain the difference between repetition, prolonged sounds, and blocking in stuttering.

i. Instructional Strategy: SLP will answer the question, "What is stuttering?" In this answer, she will give examples of the different ways that people stutter in order to let GTAs know that stuttering is not confined to one type of dysfluency.

c. Objective: Attendees should be able to discuss the potential difficulties a student who stutters may face in the public speaking classroom.

i. Instructional Strategy: SLP will answer the question, "What are the effects of stuttering?" In addition to describing situations that may increase stuttering, she will also elaborate on myths about PWS (for example, that stuttering is indicative of lower mental functioning or anxious personality traits.)

d. Objective: Attendees should be able to list 3-5 ways that someone who stutters may manage their stutter.

i. Instructional Strategy: SLP will answer the question, "What are strategies for handling stuttering?" She will explain that while stuttering is not 'curable' it is also not stagnant, and there are many ways that a person who stutters can manage their stutter. 
6. Outcome: At the end of the training session, GTAs should be able to explain the role of Student Access and Accommodation Services in regards to accommodating a student who stutters.

a. Objective: Attendees should be able to list and describe the steps that a student who stutters would go through in order to become registered with Student Access and Accommodation Services.

i. Instructional Strategy: SAAS rep will answer the question, "Walk us through the process by which a student registers with your office (for example, how do students know to register? How long does the registration process normally take?)"

b. Objective: Attendees should be able to explain the potential legal problems with accommodating a student who has not registered with Student Access and Accommodation Services (for the student, the instructor, and the university).

i. Instructional Strategy: SAAS rep will answer the question, "What are potential legal issues with a teacher accommodating a student in class if they're not registered and provided accommodations by your office?"

7. Outcome: At the end of the training session, GTAs should be able to describe the steps they would take to accommodate a student who stutters in the classroom.

a. Objective: Attendees should be able to list feedback that would be helpful/unhelpful for a student who stutters and why it would be helpful/unhelpful.

i. Instructional Strategy: SLP will answer the question, "What advice do you have for our new teachers? What are some do's and don'ts when interacting with a person who stutters?

b. Objective: Attendees should be able to list 3-5 ways that they could partner with Student Access and Accommodation Services in order to accommodate a student who stutters in the classroom.

i. Instructional Strategy: SAAS rep will answer the question, "What role do professionals like SLPs play in the accommodation process? What potential accommodations can your office and a SLP provide a student in COM 110, particularly in terms of presenting speeches? (Especially what we can do in terms of having a student read from their outline, or present their speech in the speech lab.)

ii. Instructional Strategy: SLP will answer the question, "What are some potential accommodations a SLP may give Student Access and Accommodation Services about how to accommodate a students who stutters in class? (maybe that he/she can read from a speaking outline? Maybe more time? Maybe giving the presentation in the speech lab with a smaller audience?)

c. Objective: Attendees should be able to list 3-5 ways that they could accommodate a student who stutters on a non-presentation day.

i. Instructional Strategy: SLP will answer the question, "What advice do you have for our new teachers? What are some do's and don'ts when interacting with a person who stutters? 
8. Outcome: At the end of the training session, GTAs should be able to compare how the accommodation process for a student who stutters is similar to the accommodation process for students with other disabilities.

a. Objective: Attendees should be able to explain the difference between internal/external, stable/unstable, and controllable/uncontrollable attributions.

i. Instructional Strategy: Before introducing the SLP, the trainer will have a conversation with the GTAs asking, "Why do you think we decided to focus on stuttering as a jumping off point to talk about students with disabilities?" The trainer will explain that stuttering is perceived as internal/table/controllable, when in reality it is external/unstable/uncontrollable.

b. Objective: Attendees should be able to list other invisible disabilities that students in their classes may have and discuss how they would create an accommodating environment for these students.

i. Instructional Strategy: SAAS rep will discuss a variety of invisible disabilities that are common on college campuses, such as anxiety and depression. At the end of the training, GTAs will discuss as a group, "What practical steps could you take to accommodate these students?" 


\section{APPENDIX B: SURVEY QUESTIONNAIRE}

1. From what I understand, I would guess that most stuttering is caused primarily by an underlying psychological problem.

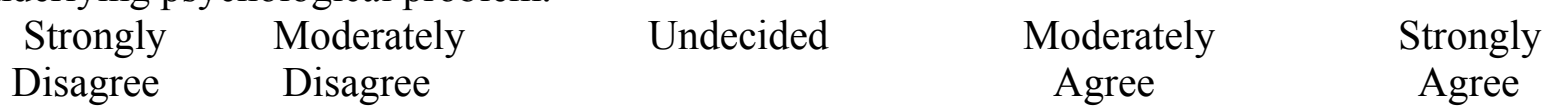

2. Generally, stutterers should be excused from talking in front of the class.

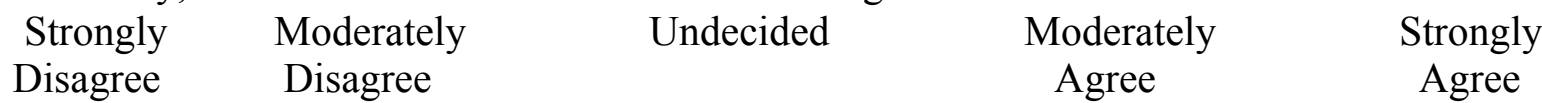

3. I would think that stuttering interferes with the stutterer's academic performance.

\begin{tabular}{|c|c|c|c|}
\hline $\begin{array}{l}\text { Strongly } \\
\text { Disagree }\end{array}$ & $\begin{array}{l}\text { Moderately } \\
\text { Disagree }\end{array}$ & Undecided & $\begin{array}{l}\text { Moderately } \\
\text { Agree }\end{array}$ \\
\hline
\end{tabular}

4. It is difficult to know how to react to stutterers in the classroom situation.

\begin{tabular}{|c|c|c|c|}
\hline $\begin{array}{l}\text { Strongly } \\
\text { Disagree }\end{array}$ & $\begin{array}{l}\text { Moderately } \\
\text { Disagree }\end{array}$ & Undecided & $\begin{array}{l}\text { Moderately } \\
\text { Agree }\end{array}$ \\
\hline
\end{tabular}

5. From what I understand, most stuttering is caused by an underlying physical problem.
Strongly
Moderately
Undecided
Moderately
Agree
Strongly
Disagree
Disagree
Agree

6. Of all the types of speech and language disorders, stuttering appears to me to be the most disruptive.
Strongly
Moderately
Undecided
Moderately
Strongly
Disagree
Disagree
Agree
Agree

7. Most stutterers can be described as being "quiet", "shy" and relatively "nonverbal".
Strongly
Moderately
Undecided
Moderately
Strongly
Disagree
Disagree
Agree
Agree

8. Teachers should avoid calling attention to the stutterer's speech.
Strongly
Moderately
Undecided
Moderately
Strongly
Disagree Disagree
Agree
Agree

9. From what I understand, most stuttering is caused by a combination of physical and psychological factors.
Strongly
Moderately
Undecided
Moderately
Strongly
Disagree
Disagree
Agree
Agree

10. A teacher should exempt a stutterer from oral or group discussions.
Strongly
Moderately
Undecided
Moderately
Strongly
Disagree
Disagree
Agree
Agree 
11. Teachers would do best to ignore the stuttering of their disfluent students.

\begin{tabular}{|c|c|c|c|}
\hline $\begin{array}{l}\text { Strongly } \\
\text { Disagree }\end{array}$ & $\begin{array}{l}\text { Moderately } \\
\text { Disagree }\end{array}$ & Undecided & $\begin{array}{l}\text { Moderately } \\
\text { Agree }\end{array}$ \\
\hline
\end{tabular}

12. Teachers should encourage stutterers to pursue careers that demand little speaking.
Strongly
Moderately
Undecided
Moderately
Agree
Strongly
Disagree Disagree
Agree

13. It is helpful to the stutterer for his/her teacher to complete words on which he/she experiences pronounced disfluency.
Strongly
Moderately
Undecided
Moderately
Strongly
Disagree
Disagree
Agree
Agree

14. It is a good policy for teachers to make students repeat stuttered words until they can speak them fluently.
Strongly
Moderately
Undecided
Moderately
Strongly
Disagree
Disagree
Agree
Agree

15. Stutterers are more fluent when teachers insist that the student relax before speaking.
Strongly
Moderately
Undecided
Moderately
Strongly
Disagree
Disagree
Agree
Agree

16. It is important for teachers to be good listeners in dealing with stutterers.
Strongly
Moderately
Undecided
Moderately
Strongly
Disagree
Disagree
Agree
Agree

17. Ridicule is a common human reaction to stuttering and may not significantly affect the stutterer's speech. Therefore, the stuttering student should learn to accept it and expect it.
Strongly
Moderately
Undecided
Moderately
Strongly
Disagree Disagree
Agree
Agree

18. Teachers have relatively little influence on the student's attitude toward stuttering; the student develops most of his/her own attitudes independently.
Strongly
Moderately
Undecided
Moderately
Strongly
Disagree Disagree
Agree
Agree

19. It is advisable for teachers to suggest that stutterers avoid certain difficult speaking situations.
Strongly
Moderately
Undecided
Moderately
Agree
Strongly
Disagree Disagree
Agree

20. It is helpful to encourage the stutterer to speak rapidly so that people will notice the stuttering less.
Strongly
Moderately
Undecided
Moderately
Strongly
Disagree
Disagree
Agree
Agree 
21. Stutterers cannot be expected to perform as well academically as non-stutterers.

\begin{tabular}{|c|c|c|c|}
\hline $\begin{array}{l}\text { Strongly } \\
\text { Disagree }\end{array}$ & $\begin{array}{l}\text { Moderately } \\
\text { Disagree }\end{array}$ & Undecided & $\begin{array}{l}\text { Moderately } \\
\text { Agree }\end{array}$ \\
\hline
\end{tabular}

22. There is no relationship between fear and stuttering.
Strongly
Moderately
Undecided
Moderately
Strongly
Disagree Disagree
Agree
Agree

23. Stutterers can in general be considered as being psychologically different from normal speaking students.
Strongly
Moderately
Undecided
Moderately
Agree
Strongly
Disagree
Disagree
Agree

24. Teachers should caution the stutterer to think before he/she speaks.
Strongly
Moderately
Undecided
Moderately
Strongly
Disagree
Disagree
Agree
Agree

25. Teachers should advise the stutterer to take a deep breath before speaking.
Strongly
Moderately
Undecided
Moderately
Strongly
Disagree
Disagree
Agree
Agree

26. Stutterers are generally not as responsible as non-stutterers.
Strongly
Moderately
Disagree
Disagree
Undecided
Moderately
Strongly
Agree
Agree

27. Stuttering may be viewed as a preliminary sign of character weakness.
Strongly
Moderately
Undecided
Moderately
Agree
Strongly
Agree

28. Allowances should be made in the evaluation of a stutterer's academic performance.
Strongly
Moderately
Undecided
Moderately
Strongly
Disagree
Disagree
Agree
Agree

Imagine that tomorrow a new student will be enrolling in your basic communication course. This student has a noticeable stutter. Please indicate your level of agreement with the following statements.

29. I would feel anxious interacting with this student.
Strongly
Moderately
Undecided
Disagree
Disagree
Moderately
Agree
Strongly
Agree

30. I believe this student is shy or fearful.
Strongly
Moderately
Undecided
Disagree
Disagree
Moderately
Strongly
Agree
Agree

31. I have the resources I need to accommodate this student. 
42. Do you currently have a stutter, or have you experienced a stutter in the past?

○ Yes

○ No

43. Do you have a close relationship with someone who stutters?

○ Yes

○ No

44. Do you currently or have you previously taught a student who stutters?

○ Yes

○ No 


\section{APPENDIX C: SAMPLE OF FOCUS GROUP QUESTIONS}

1. What was the most beneficial, or most influential, part of the training session?

2. What was the lease beneficial, or least influential, part of the training session?

3. What surprised you most about the training session?

4. What was beneficial or not beneficial about hearing from a Speech Language Pathologist?

5. What was beneficial or not beneficial about hearing from the student disability services office?

6. What would you change in a future training session? 


\section{APPENDIX D: QUANTITATIVE RECRUITMENT EMAIL}

Dear Instructor,

You are invited to participate in a research study conducted by Jillian Joyce under the supervision of Dr. Lance Lippert. Jillian Joyce is a researcher from the Illinois State University School of Communication. We hope to discover individual attitudes, knowledge, and beliefs instructors have about students who stutter, specifically in the basic communication course classroom.

The survey is not examining general disfluency (for example, students who stammer when they are nervous), but rather students who experience the diagnosable disorder of stuttering. In order to participate in this survey, must be at least 18 years of age.

If you decide to participate, you will complete a four-part survey that will take about 10-15 minutes to complete.

There is a chance you may experience distress if you yourself or someone who know experienced a negative occurrence due to a communicative disability. If you experience distress while taking the survey and need help regarding a disability, please visit the Student Access and Accommodation Services office website: http://studentaccess.illinoisstate.edu/ or contact the office directly at (309) 438-5853.

Your participation is voluntary. The directors of the Graduate Teaching Assistant program will not know who has decided to participate. Your decision whether or not to participate will not affect your relationship with Illinois State University. If you decide to participate, you are free to withdraw your consent and discontinue participation at any time without penalty. Individuals who choose to participate in this study are assisting researchers in learning more about attitudes, knowledge, and beliefs about students who stutter, as well as helping researchers 
develop strategies to accommodate these students in the basic communication course classroom. Your survey responses will be anonymous.

If you have any questions about the study, please feel free to contact Jillian Joyce at (702) 2037830, jajoyc1@ilstu.edu. You may also contact Dr. Lance Lippert at (309) 438-7329, 1lipper@ilstu.edu. If you have questions regarding your rights as a research subject, you are encouraged to contact the Illinois State University Office of Research, Ethics, and Compliance at (309) 438-2529 (REC@illinoisstate.edu).

By clicking begin, you indicate that you have read and understand the information provided above, that you willingly agree to participate, that you may withdraw your consent at any time and discontinue participation without penalty.

https://survey.lilt.ilstu.edu/TakeSurvey.aspx?SurveyID=78KK5n300 


\section{APPENDIX E: QUALITATIVE RECRUITMENT EMAIL}

Dear Instructor,

I am a graduate student under the direction of Dr. John Baldwin in the School of Communication at Illinois State University. I am conducting a research project about basic course instructors' perceptions and attitudes about students with disabilities, as well as their self-efficacy in accommodating these students. Specifically, I am seeking feedback on the 'Classroom Management and Special Populations' section of the Graduate Teaching Assistant Training course.

I will be conducting focus groups to gain opinions about the training course. Each focus group will consist of 4-8 participants who also attended the training session. Feedback from focus groups will help researchers to assess the training and make any adjustments to improve the training in the future.

Focus groups will be conducted in Fell Hall on the ISU campus. Participation is completely voluntary. Because of the nature of focus groups, complete confidentiality cannot be guaranteed. However, all participants will be given pseudonyms in any published material and no personal identifying information will be revealed.

These interviews will be audiotaped/videotaped, and each focus group should last between 45-60 minutes. Your decision whether or not to participate will not affect your relationships with Illinois State University. If you decide to participate, you are free to withdraw your consent and discontinue participation at any time without penalty.

There is a chance you may experience emotional discomfort while discussing opinions and personal examples regarding your experiences in accommodating students with disabilities. If you experience distress during the focus group and need help regarding a disability, please visit 
the Student Access and Accommodation Services

website: http://studentaccess.illinoisstate.edu/ or contact the office directly at (309) 438-5953.

Individuals who choose to participate in this study are assisting researchers in learning more about instructors' attitudes regarding their students, and helping develop a strong training program for future Graduate Teaching Assistants.

Please direct any questions and/or comments to Dr. John Baldwin (jrbaldw@ilstu.edu) or to me. If you have any questions about your rights as a subject/participant in this research, or if you feel you have been placed at risk, you can contact the Research Ethics \& Compliance Office at Illinois State University at (309) 438-2529.

If you are interested in participating, please contact me as soon as possible to coordinate a time and date for the focus group. I can be reached as jajoyc1@ilstu.edu. Focus groups can begin as early as this week. If you are available before Thanksgiving break begins and would like to participate, please let me know. 